\title{
THE 1940 STATEMENT OF PRINCIPLES ON ACADEMIC FREEDOM AND TENURE
}

\author{
WAlter P. Metzger*
}

In the field of American higher education, prescriptive dicta concerning academic conduct seldom exhibit much staying power. Some are meant to be ephemeral, to answer a transient public criticism with an immediately placating response. Some are designed for longer duty but are quickly reduced by the swift pace of events to a remnant of a changing geist and then to a relic of a forgotten past. Especially short is the life expectancy of pronouncements on the proper scope of academic freedom and the proper terms of employment of faculty personnel. On such subjects, the collective expressions of academic groups, especially if they seek improvement on a global scale, seem to pass from birth to eternal rest at the speed with which American foundations finance academic conferences with similar agendas or one edition of the Chronicle of Higher Education is followed by publication of the next.

One of the arresting features of the 1940 Statement of Principles on Academic Freedom and Tenure ${ }^{1}$ is its exceptional durability. Compared with the high infant mortality rate of its species, its ability to stay alive for as long as fifty years stacks up as a Methuselah accomplishment. That it stayed alive during the last fifty years makes its longevity all the more remarkable. Born to an academic world that was relatively small, self-contained, and stable, it came of age in a world that had grown immense, delocalized, and volatile. Nevertheless, except for the reinterpretation in 1970 of certain illegible or outmoded passages, it has managed without amendment to take these transforming years in stride. It has weathered any number of roller coaster swings: the rise and fall of McCarthyism, the flow and ebb of student riotousness, and the feasts and anticipated famines of college student enrollments. It has survived the quickening of academic trends that had been set in motion prior to 1940 , such as the steady decline in the share of material

\footnotetext{
Copyright (C) 1990 by Law and Contemporary Problems

* Professor of History, Columbia University.

1. 1940 Statement of Principles on Academic Freedom and Tenure ("1940 Statement"), in Policy Documents and Reports 3 (AAUP, 1984) ("1984 AAUP Red Book"); see Appendix B, 53 L \& Contemp Probs 407 (Summer 1990). All references to the 1940 Statement in this article are to the text that was written in 1940, the historic text, and not to the text edited in 1990 to remove gender-specific references. Contrast 1940 Statement, in Policy Documents and Reports 3 (AAUP, 1990) ("1990 AAUP Red Book"). This is done in a Rankean spirit-to record the event as much as possible wie es eigentlich gewesen ist.
} 
and human resources going to the private sector of American higher education and the rise in the public sector of multicampus universities under statewide systems of control; it has survived the initiation and acceleration of trends that had hardly been sighted before 1940 , such as the spread of faculty unionism and the rise of the federal government as a major academic rulegiver and financier. If it deserved no other praise, the 1940 Statement would merit admiration for its hardiness in the face of incessant, often rapid, sometimes convulsive, change.

But it is not on this ground alone that we who are academics find it praiseworthy; were we inclined to honor mere persistence, no matter how marginal or vestigial, we would pay homage to the vermiform appendix. As it happened, this holdover from another era, far from paying for the gift of life with loss of function, has added to its significance as it aged. During the first two decades of its existence, it secured the endorsement of no more than a handful of learned societies and academic administrative associations. During the 1960s, it gained the backing of as many as sixty-five such legitimizing bodies; during the 1970s, when stock-taking on academic freedom and, especially, academic tenure came into vogue, it suffered but one organizational defection and picked up thirty-five new subscribers; during the 1980 s and early 1990 s, as though to demonstrate that its charms were ageless, it added thirty-four new endorsers to the list. ${ }^{2}$ Moreover, as time wore on, more and more colleges and universities (they have not been counted but they are surely numerous) saw fit to incorporate bits and pieces of it into their regulations, or by reference or quotation to embrace it whole. In the field of law, it seems not to have had much of an impact until the $1970 \mathrm{~s}$, when a spate of contested academic discharges on grounds of financial exigency led lawyers and judges to use it as an authoritative guide to academic usage on that subject; thereafter, it would be paid the compliment of citation when the courts sought to explicate other terms of faculty employment contracts. ${ }^{3}$ Only with respect to professional self-regulation may it be said that the 1940 Statement did not put on weightiness late in life, and this is because, to the American Association of University Professors ("AAUP"), the chief nonlegal monitor of academic freedom and tenure in this country and the co-author and primary user of this document, it was of signal importance from the very start.

Even its celebrants will admit that the 1940 Statement has not been a hit in all academic quarters. A roll call of its endorsers would disclose the conspicuous absence of the American Council on Education, the Association of American Universities, and several other prominent members of the academic administrative establishment. In institutions where the reflexive

2. 1990 AAUP Red Book at 7-10 (cited in note 1).

3. In the four-year period, 1972-1976, a computer search by then AAUP staff counsel David Rabban found that the 1940 Statement and documents based on it figured in forty-nine federal court decisions. It played a prominent role in state court decisions during this period as well, starting with the landmark case of American Assoriation of Univerity Professors v Bloomfield College, 129 NJ Super 249 , 322 A2d 846 (1974), aff'd, 136 NJ Super 442, 346 A2d 615 (1975). 
cautiousness of the house attorney is allowed full sway, allusions to the 1940 Statement in bylaws and handbooks may be accompanied by a boilerplate reserve clause disclaiming any legal obligation to adhere to some or any of its terms. And in institutions, highly visible but still quite few, where universal limited-term appointments are the rule, the 1940 Statement has obviously been ignored or recanted. But these evidences of standoffishness or opposition are not surprising: one does not expect everyone in this fractured and diverse domain to give unreserved consent to anything. What is surprising is that support for the 1940 Statement cuts across so many internal divisions. These include divisions between administrators and professors, first and foremost; divisions between public and private, church-connected and independent, teaching-oriented and research-oriented institutions; and finally, divisions between the specialist profession of the "discipline" and the ecumenical profession of the "faculty"-the two academic professions that both liberate their overlapping memberships by sanctioning dual loyalties and oppress them by generating counterpulls. When and if the time comes to write the funeral address for the 1940 Statement, the fair memorialist will stress, not that it went just so far, but that it bridged so much.

\section{II}

\section{IL Nome! Il Nome!}

All in all, the fifty-year record of the 1940 Statement gives us abundant cause to salute it for its vitality - a virtue greater than mere endurance-and to pay tribute to its growing usefulness-a rare accompaniment to advancing age. But what is this thing we so proudly hail? To what works, seemingly unrelated, does it have a cognate connection; from what works, superficially alike, does it really stand apart? At first glance, an easy answer to the question of identification, which always shades into a question of classification, would seem to be ours for the asking. Ordinarily, objects that are hard to categorize are also hard to utilize and hence are unlikely to be roundly praised. In this case, however, the generic identity of a much-used object has proved elusive. Like Elsa plighting her troth to the cryptic Lohengrin, American academics and others have embraced the 1940 Statement without knowing its family name.

On this score, those who know it best and love it most-the leaders of the AAUP-may offer limited enlightenment. Around a decade ago, Ralph S. Brown and Matthew W. Finkin, veteran members of the AAUP's national Committee on Academic Freedom and Tenure, widely known as Committee A, described the 1940 Statement as the "Bible" and "Constitution" of their organization and, by extension, of the entire American academic profession. ${ }^{4}$ These level-headed law professors were not descending into flights of utter fancy; some broad affinities do exist between this creation of their microcosm

4. Ralph S. Brown, Jr. \& Matthew W. Finkin, The Usefulness of AAUP Policy Statements, 59 Educ Rec 30 (1978). 
and those two world-historic masterpieces. Like the Book of Books, like the federal Constitution, the 1940 Statement does satisfy a hunger for standards of goodness and justice that are less fickle than those favored by contemporary opinion, more universal than those available to local wisdom, and more disinterested than those promoted by partisans in fighting dress. In addition, these analogies help to bring out qualities in the work that might be missed in a casual perusal of it. Likening the 1940 script to Holy Scripture calls attention to the aura of sacrosanctness it has acquired within the AAUP over the years. These are secular precincts; nevertheless, when it performs its work of the guardian variety, Committee $A$ incants the words and phrases of the 1940 Statement with a reverence usually reserved for the hymning of a doxology, and the AAUP Washington staff ponders its every word with an exegetical skill that invites comparison with that of gospel hermeneuts and Talmudic scholars. In the same sense, there is something to be said for likening the handiwork of 1940 to the magnum opus of 1789. The comparison underscores the symbiosis between rules and cases; in both instances, the norms embodied in a governing text help tell rights from wrongs in specific controversies, while the clarifying factuality of specific controversies refreshes the normative commands of the governing text. And this comparison may highlight aspects of the 1940 Statement that would otherwise go unremarked, such as its sectional structure, its enumerated subparts, its extreme succinctness, and the fact that its words and phrases have but one definitive interpreter.

But no one seriously supposes that these flamboyant figures of speech can put the "what-is-it?" question to rest. Obviously, it would strain comparison to the snapping point to imply that there was anything Biblical about the literary style of the 1940 Statement: anyone who has read the dry, spare prose of this two-page document (five pages counting footnotes and interpretive commentary) does not have to be told that it fails to capture the sublimity of the Book of Genesis or the lyricism of the Book of Psalms. Given their way with words, the authors of this document, had they undertaken to rewrite the Pentateuch, would probably have called it the 1200 B.C. Statement on Divinized Administrative Policy Affecting Certain Classes of Israelite Personnel! Here, perhaps, hyperbole is too blatant to be misleading. But in the analogy between the 1940 Statement and the Constitution, the exaggeration is sufficiently muted to foster a false impression. Brown and Finkin sought to convince the courts that the contractual obligations of the institutional subscribers to the 1940 Statement were defined by the AAUP's later interpretation of its elliptical language, especially its one-sentence reference to terminations of faculty employment for financial reasons. To drive home the point that the original verbiage should be read in the light of the AAUP's subsequent constructions, they hit on a metaphor they were sure every judge would appreciate. "In its form and language," they and their confreres wrote in an AAUP amicus brief, "the 1940 Statement resembles a constitution. Like other 'constitutions', [it] has generated 'legislation'- 
supplemental statements and recommended institutional regulations-and 'judicial' interpretations-reports of investigations into cases involving potential departures [which] supply a gloss that helps define its meaning."5

Judges, as it turned out, were not all that appreciative of this kind of artful reasoning by analogy. In the immediate case, the court ruled that the AAUP's version of the 1940 Statement lacked legal effect because it was formulated after the execution of the faculty employment contract referring to that document; ${ }^{6}$ in other cases, judicial resistance to the AAUP's approach centered on the status differential between a widely endorsed professional statement and a unilateral reading of it by one of its authors. ${ }^{7}$ Apparently, no one took exception to the forensic use of the 1940 Statement as a violation of its original intent-yet this, to the historian, if not the lawyer, is a crucial point. Those who wrote the 1940 Statement put their words to paper long before academic freedom had entered the protective folds of the first amendment and some time before academic tenure had acquired strong advocates on the bench or many statehouse friends. Their animating assumption was that the defense of these professional goods would have to lie outside the law, in the perfection of the policies and practices of institutions of higher learning. Their aim was to elevate academic conduct to a high uniform standard; their means-an inventory of "do's" and "don'ts"-reflected their belief that, since the law allows academic institutions to be run like so many extraterritorial enclaves imposing rules of their own devising on the native population, the only way to achieve that elevation was through moral, not legal, prodding. That the words they concocted for that purpose might be used to affect the outcome of courtroom battles seems to have been furthest from their minds. This inference can be drawn from the authors' failure to consider the legal implications of their language in their writing conferences, from the fact that very few of the conferees had legal training, and from the unlawyerly frequency with which undefined and vague terms were preferred for the flexibility they afforded to words that were well defined and clear. In time, the courts would become more accommodating to the concerns of academic employees, and the 1940 Statement, as indicated, would become a litigatory resource. But, as a rule, the original function of an object, and not its later adaptation, is better able to tell us what it is. Instructed only by the AAUP's gifted metaphorists, one would hardly suspect that the 1940 Statement was put on earth not to reinforce legal claims, but to provide a feasible substitute for them.

If we cannot rely with complete confidence on the closest friends of the 1940 Statement to define it, may we rely on the work itself to spill the beans? Undoubtedly more can be learned from a scanning of the text than from insightful but extravagant analogizing. But the text does not speak for itself,

5. AAUP's Brief as Amicus Curiae at 31-32, Schener v Creighton University, 199 Neb 2d 618, 260 NW2d 595 (1977).

6. $199 \mathrm{Neb} 2 \mathrm{~d}$ at $630,260 \mathrm{NW} 2 \mathrm{~d}$ at 600.

7. See, for example, Browzin v Catholic University of America, 527 F2d 843, 847-48 (DC Cir 1975). 
as one soon discovers when one looks in its body for confirmation of the promise of its title. The authors of this document did not call it a "statement on academic freedom and tenure"; they called it a "statement of principles on academic freedom and tenure." The use of this intermediating word was not a slip of the drafting pen. One group of participants, hoping to fashion a document that would enscribe convictions rather than hard and fast regulations, and that would invite trustee approval rather than adoption, thought the insertion of a nicely general and uncoercive word like "principles" would do the trick; the other group, with quite opposite intentions but also fearful that many trustees would resist anything that smacked of central code-writing, went along. "Principles," which is to say, fundamental credenda, not practical rules, are what the 1940 Statement tells us it is about.

Up to a point, the document lives up to its own billing. Certainly, its preamble, like most preambles, sticks to a high level of abstraction. Its four annunciatory declarations - that institutions of higher education exist not for themselves but for the "common good"; that academic freedom is "essential" to that purpose; that academic tenure is "indispensable" to academic freedom no less than to academic job security; and that "academic freedom carries with it duties correlative with rights"-are presented not as policies to be enacted but as articles of faith to be professed. And most of the next section on "academic freedom" is also filled with pithy propositions of lofty sweep. Here the authors recorded their belief that academics were entitled to three kinds of freedom, each corresponding to a major function or activity: "freedom in research and in the publication of results"; "freedom in the classroom in discussing (the teacher's) subject"; and "freedom from institutional censorship" when the teacher "speaks or writes as a citizen." Reiterated in Committee A reports, institutional regulations and legal briefs, these three axiomatic dedications to principle would become extremely familiar to American academics over the years. This is not to say that they ever became altogether platitudinous or even entirely noncontroversial. If it is now almost universally agreed that academic freedom is essential to a university, the one grace the institution may not lose without losing everything, it is far from obvious to everyone that academic tenure is academic freedom's needed handservant. And though most who do these conceptual mappings divide academic freedom, like Caesar's Gaul, into three main parts, some insist that good logic would divide it into only two (freedom to teach and freedom to do research, arguably the only professionally relevant freedoms, with citizen or extramural freedom ceded to the large neighboring country of ordinary civil liberties), ${ }^{8}$ and a few would divide it into four (the three that go with the

8. For views in favor of a two- rather than three-ply definition of academic freedom, see Stephen R. Goldstein, Academic Freedom: Its Meaning and Underlying Premises in the American Experience, 11 Israel L Rev 52 (1976); William W. Van Alstyne, The Specific Theory of Academic Freedom and the General Issue of Civil Liberties, 404 Ann Am Acad Pol \& Soc Sci 140 (1972). For views against the displacement of extramural freedom, see Thomas I. Emerson \& David Haber, Academic Freedom of the Faculty Member as Citizen, 28 L \& Contemp Probs 525 (Summer 1963). For institutional autonomy as a feature of 
faculty's roles plus one attached to the students' status) ${ }^{9}$ or even five (all of the four individual academic freedoms, along with institutional academic freedom, also known as institutional autonomy). ${ }^{10}$ It would by no means be true to say that, where the 1940 Statement is couched in the rhetoric of principles, it gives itself over to trite deliverances or empty gab.

But a good part of the 1940 Statement is not couched in the rhetoric of principles. Some matters are first flung into the conceptual air and then brought back to earth by the gravitational pull of quite concrete concerns. In the academic freedom section, the authors could not resist interspersing mundane operational details with canonical pronouncements under each of the three subheadings. In the last section on academic tenure, their interest in the particulars of policy emerged full force. They did start this section by distinguishing between the "principle" of academic tenure (which they reduced in one sentence to the precept that faculty members should be retained indefinitely, if they are retained at all, after a period of probation) and the implementation of academic tenure (to which they gave over the rest of the section, stressing the importance of a trial period of fixed duration and a dismissal procedure in accord with specified elements of due process). To avoid the appearance of legislating in detail for governing boards jealous of their prerogatives, the authors characterized the second as merely representing "acceptable academic practice," that is, as a recommended but not obligatory interpretation of the principle, which alone required universal assent. But distinctions do not live on tag words alone, and it was not lost on some of these wordsmiths that a failure to follow the only modus operandi elaborated or even mentioned in this section would be taken as a failure to abide by the principle as well. At all events, in the cauldron of actual cases, "may" did dissolve into "must," and adherence to the tabular and judicial niceties of tenure became as requisite to the AAUP guardians as commitments placed on a more conceptual plane. In sum, the 1940 Statement manages to combine what it advertises and in part displays as a set of principles with what it never labels but in fact promotes as a set of rules. Alas for tidy categorizing! In this respect, the 1940 Statement is not a pure strain but a crossbreed, one part theorist's exercise and one part operator's manual, a kind of elephant with stripes.

Or is it a horse of wholly different color? In the 1940 Statement, each passage entitling faculty members to a different kind of academic freedom is followed by a clause or sentence introduced by "but" and laden with

academic freedom, see J. Peter Byrne, Academic Freedom: A "Special Concern of the First Amendment," 99 Yale L J 251 (1989).

9. See Philip Monypenny, Toward a Standard for Student Academic Freedom, 28 L \& Contemp Probs 625 (Summer 1963); Developments in the Law-Academic Freedom, 81 Harv L Rev 1045, 1128 (1968).

10. See Comment, Testing the Limits of Academic Freedom, $130 \mathrm{U}$ Pa L Rev 712 (1982). The geography of academic freedom can be configured in all sorts of ways. For a three-part definition that brings together public school teachers fighting government control, professorial teaching and research freedom, and institutional autonomy, see Mark Yudof, The Three Faces of Academic Freedom, 32 Loyola L Rev 831 (1987). 
messages to faculty members admonishing them to do right things. Without more knowledge of the authors' intentions than the text supplies, one cannot tell whether each freedom was granted on condition that the precepts conjoined to it were obeyed, or whether each series of "shoulds" sets the outer boundary of a freedom that was, up to that edge, granted to every faculty member unconditionally, or whether, indeed, the postscripted materials were neither meant to be quids that paid for quos, or markers that described the scope of privileges, but merely words to the wise that the recipients of each entitlement were asked to live by but could with impunity ignore. Nevertheless, though the 1940 Statement leaves their status quite unclear, these exhortations to professional good behavior do suggest to some that the document finds its closest parallel to the Principles of Medical Ethics of the American Medical Association, or the Canon of Legal Ethics of the American Bar Association, or the attempts by a host of other professions to raise the ethical standards of their members by code and, in consequence, by deed.

The 1940 Statement may have the makings of a professional code of ethics, but it says too little on that subject to have the typical markings of one. ${ }^{11}$ Most professional codes pay close attention to how professionals should behave toward one another: calls for mutual civility, strictures against undercutting, comments on the proprieties of referral-these concerns with professional comity bulk large in undertakings of this kind. By contrast, the 1940 Statement totally ignores the etiquette of peer relationships (with one exception-it gives a modest amount of instruction to faculty members called upon to judge the professional fitness of their own colleagues). Again, most professional codes dwell on the obligations of the professional practitioners to society, enjoining them to render gratuitous services to the needy, to maintain a high level of training, and to prevent quackery and chicane from taking root. The 1940 Statement, in a barrage of "shoulds," does refer to the obligations of academics in their role as citizens. But the obligations it refers to are not owed to the public; they are owed to the academics' institutions, which supposedly stand to suffer the displeasure of the public when these obligations are contravened. Finally, all but radical sociologists and deepdyed cynics would agree that one of the hallmarks of professionalism is its unequivocal, if not wholly selfless, devotion to the best interests of the client. A code of professional ethics that failed to disavow conflicts of interest, specify fiduciary responsibilities, or put in other good words for altruism, would strike the cynics as curiously candid and others as unworthy of its name. With one ambiguous exception, however, the 1940 Statement ignores the professional-client relationship. It does say, ostensibly on behalf of

11. In a vast literature, the following works on professional codes of ethics are particularly relevant to this discussion: The Ethics of Professions and of Business, 101 Ann Am Acad Pol \& Soc Sci (1922); Ethical Standards and Professional Conduct, 297 Ann Am Acad of Pol \& Soc Sci (1955); Carl F. Taeusch, Professional Ethics, in Edwin R. A. Seligman, ed, 12 Encyclopaedia of the Social Sciences 472 (Macmillan, 1954). 
students, that faculty members in their classrooms should avoid "controversial discussion unrelated to their subject," but this single piece of proclient moralizing hardly touches on the worst teaching offenses and itself embodies a dubious pedagogy. Further evidence that the 1940 Statement does not belong in a conventional ethological box lies in the fact that in $\mathbf{1 9 6 6}$ the AAUP adopted a separate Statement on Professional Ethics that covered all the professional relationships given short shrift a quarter of a century before. ${ }^{12}$

Obviously, a document so full of "shalts" and "shalt nots" does bear the imprint of the ethicist's imagination. What makes this document so hard to place is the "thou" to which that imagination is addressed. The commandments of the 1940 Statement are not aimed exclusively-or even primarily-at the academic professional; they are aimed, with the noted exceptions, at the academic professional's employer. As here defined, academic freedom denotes a set of functional zones in which faculty members may express themselves, free from the dictates of their institutional employers. These "no trespassing" signs are not turned against the external power of the state or church (as they are on the European continent, where the studium engaged in a historic battle against the imperium and sacerdotium), nor does this kind of zone defense serve to restrain professorial insiders, who are painted as the rightful possessors, and not as the potential deprivers, of academic freedom rights. Similarly, as here defined, tenure is a set of rules designed to remove from the dismissal process the arbitrariness and intolerance that institutional authorities may be able to display in legal safety. Although the concept of judicialized tenure also requires faculty members to adhere to due process when they are cast as judges, there is no doubt that the 1940 Statement holds trustees and presidents mostly responsible for institutionalizing forbearance and fair play. In addition, the material costs of tenure rules (such as the award of at least a year's salary to a teacher dismissed for reasons other than moral turpitude) are billed to the institution's treasurer, and the transmutation of all these injunctions into policy requires enactment by the institution's governing board. If one were to persist in regarding the 1940 Statement as a code of ethics, one would have to admit that it is a strange one-a managerial code that, for some mysterious reason, takes pains in one of its parts to salt in some professional ethics too.

Somewhat strange it may be, but the 1940 Statement is not so unusual that it bears no illuminating likeness to other things. To place it in its class, one

12. Statement of Professional Ethics, in 1990 AAUP Red Book at 75 (cited in note 1). This statement was revised by its AAUP author in 1987. In addition, the association has addressed particular ethical problems (such as resignation of faculty members, conflicts of interest in government research, rights and freedoms of students, faculty responsibility in campus demonstrations, plagiarism, and discrimination). Where possible, these pinpointed comments attempt to draw their authority from words in the Ur-text, the 1940 Statement, especially from the declaration that academic freedom "carries with it duties correlative with rights." But the AAUP made sure that none of the above ethical issues that were lively at that time, such as the proper protocol for faculty resignations, got into the 1940 Statement itself. 
must turn from metaphors that are offered tongue in cheek and textual clues that may be misleading to the nominative possibilities opened up by historythe legislative history of the document and the occupational history of the profession. The legislative history, which begins as far back as 1915, tells us that the 1940 Statement may profitably be studied as a pact; the occupational history, starting with the crisis of the Great Depression, tells us that the 1940 Statement may be helpfully understood as the prompter of a great reform. In romantic opera, the quest for hidden names ends in a denouement of divulgence, after which the curtain abruptly falls. In this paper, pact and reform are not given as climactic revelations designed to forestall further inquiry. But they may be taken as identification tags without which this Pimpernel is likely to remain damnably elusive.

\section{III}

PACT

It is common knowledge that the 1940 Statement was co-authored by representatives of the AAUP and representatives of the Association of American Colleges ("AAC"), an organization composed of undergraduate academic institutions and run by their top administrators. This knowledge, however, has not commonly excited much curiosity-and it should. Why, it is reasonable to ask, did the only organization in America dedicated to the advancement of academic freedom and tenure need administrators to help them tell the world how this might best be done? Why did the AAUP professors share writing honors with an organization of college presidents, whose institutional interests and personal belief systems were not likely to be wholly consonant with their own? If it is true that in such matters opposites attract (though sworn enemies surely would not), why did the AAUP join with only one segment of the executive set-the part affiliated with the AAC? And, to come to the point of this questioning, what does the 1940 Statement owe to the fact that it is a pact and what to the identity of the pact-partner?

One thing is clear: the leaders of the AAUP did not go looking for coauthors because they were at a loss for words. On the contrary: from the moment of its creation, the association was in the hands of academics who proved to be the nation's most effective expositors of the meaning of academic freedom and most eloquent advocates of desirable tenure rules.

In 1915, the infant AAUP set up a committee of distinguished professors, chaired by the Columbia economist, E.R.A. Seligman, and captained by the Johns Hopkins philosopher, Arthur O. Lovejoy, to prepare a treatise on academic freedom and tenure that would clarify and justify concepts long considered in many lay and academic circles as dubious or arcane. The document that emerged after a year of deliberation-a twenty-page Declaration of Principles, also known as the Seligman Report-was instantly acclaimed by AAUP members as a work of seminal significance; gradually it 
would acquire in wider circles the reputation of a minor classic. ${ }^{13}$ As would be true of its descendant a generation later, the word "principles" in its title did not quite accurately describe its contents. In this case, the term was a misnomer, not because the authors commingled policies and precepts (insofar as they were rule minded, they relegated what they called "practical proposals" to a clearly marked appendix), but because, despite the obvious need for brevity, they refused to reduce their value judgments to a few unargued propositions. Theirs, they felt, was to reason why, and their reasoning, which borrowed from intellectual history and social philosophy as well as from practical ethics, was intended to provide a rationale founded on a coherent, if not elaborately embroidered, theory.

Utilitarian in temper and conviction, the theorists of 1915 did not view the expressional freedoms of academics as a bundle of abstract rights. They regarded them as corollaries of the contemporary public need for universities that would increase the sum of human knowledge and furnish experts for public service-new functions that had been added to the time-honored one of qualifying students for degrees. Still, although they tied this functional defense of academic freedom to the new gnostic missions of the academy, they ransacked old stores of philosophy to make their case.

The marketplace libertarianism of J. S. Mill is evident in their contention that truth is never finally possessed but must be endlessly discovered, and that error is best corrected not by the pre-emptive use of power but by the competitive play of minds. The Pauline notion of stewardship lurks in their insistence that the governing boards of private academic institutions, like the governing boards of public ones, are not vested with the prerogatives of owners but are burdened with the obligations of fiduciaries, and that they are ultimately accountable not to gift givers or taxpayers, but to the whole society, a trust relationship that extends not only to the society in being but also to the society in prospect, to a posterity that has as yet no voice. The Coleridgean idea of clerisy, intermixed with "new class" claims stretching back to the Comtean Enlightenment, can be detected in the authors' assertion that academic professionals, by virtue of their special gifts and training, possess the ability to make veridic judgments in their disciplines that the laymen who appoint them lack, and that they should therefore be free of lay interference when they act as resident agents for their specialties and counselors to society

13. General Report of the Committee on Academic Freedom and Academic Tenure, 1 AAUP Bull 17 (December 1915) ("1915 Declaration"); see Appendix A, 53 L \& Contemp Probs 393 (Summer 1990). When presented to the AAUP's January 1916 annual meeting, this document bore a leaden title, which dropped out of sight before it could get into the swim of history. It came to be called the Seligman Report in deference to the chairman who composed its first draft, though with greater justice it might have borne the name of Lovejoy, who made major substantive and linguistic changes in the text. It also came to be called the "1915 Declaration of Principles," a rubric that covers ninetenths of the text and all its analytic contributions, although the authors used that heading to refer only to its first section. In this article, the latter title will be used. In referring to the "authors" of this document, this article alludes not to Seligman and Lovejoy alone, but to the members of the committee, most of whom passed on drafts and some of whom (especially Franklin Giddings of Columbia, and Frank A. Fetter and Howard C. Warren of Princeton) made important contributions to it. 
on call. And a medley of Shakespearean and Galilean quotations could be heard in their repeated warning that academics must be and must seem to be dispensers of the results of their own independent investigations rather than vehicles for the opinions of their paymasters, an appeal to the scientists' conscience that echoed the precept, "to thine own self be true." No matter where they originated, these functional arguments had a common terminus: it is for society's sake, not for their own sakes, that professors must be academically free; professors can be academically free only if those in charge of universities concede that the latter must not, as corporate bodies, have truths to speak for or errors to suppress.

The idea of institutional neutrality-the view that a university cannot put the stamp of its approval or disapproval on a disputed truth-claim and still be faithful to its social trust-was of such critical importance to these authors that they highlighted it in almost every paragraph, though they did not refer to it by that name. Lest institutional neutrality seem too bloodless an idea to rise to sine qua non importance, they resorted to colorful figures of speech to describe it. They likened the operation of the neutral norm to the separation of executive and judicial powers at the federal level: "with respect to the conclusions reached and expressed by them," university teachers should be understood as "no more subject to the control of trustees, than are judges subject to the control of the President," and "trustees are no more to be held responsible for, or to be presumed to agree with, the opinions and utterances of professors, than the President can be assumed to approve of all the legal reasonings of the courts." To this end, too, they utilized another domestic image, one drawn from higher education. A university, they wrote, should be "an intellectual experiment station, where new ideas may germinate and where their fruit, though still distasteful to the community as a whole, may be allowed to ripen until finally, perchance, it may become part of the accepted intellectual food of the nation and of the world." The authors well knew that academic governing boards in this country were under no legal compulsion to treat their institutions as inviolable refuges for seedling thoughts. They hardly had to be told that the constitutional law of the land and state laws on academic incorporation safeguarded the right of churches to found colleges that would propagate their version of religious truth, that the tax laws were too undeveloped to favor charity for propaedeutics over charity for propaganda, and that ideological dismissals from private and even public institutions were not usually redressible in the courts. They believed, however, that they could take cognizance of these legal realities without deferring to them. Any university, they wrote, "which lays restrictions upon the intellectual freedom of its professors proclaims itself a proprietary institution, and should be so described whenever it makes a general appeal for funds; and the public should be advised that the institution has no claim whatever to general support or regard."

The theory of academic freedom erected on these foundations allowed the authors of the 1915 Declaration to redesign the interior spaces of academic 
freedom, heretofore drawn to German specifications that had never been fully in touch with American academic life. These theorists had no room in their blueprint for Lernfreiheit or student freedom; only faculty members were to be the beneficiaries of their call for trustee restraint. They expanded the boundaries of Lehrfreiheit to include not only the freedom of the faculty to teach and do research without fear of censorship-the German two-part convention-but also the freedom of the faculty to talk and write about matters outside their certified area of competence and unrelated to their professional duties. This was the first authoritative enunciation of the trinitarianism that in 1940 would emerge in barer form. Their stated reason for tacking on extramural speech was a circumstantial one: the AAUP had found that professors were more likely to be punished for expressing unpopular ideas in a public forum than for anything they said in the classroom or did in the lab. They were also concerned that the denial to academics of the rights of citizens would make it difficult to attract able people into the profession. They had an implicit but compelling third reason, and it was derived from the logic of institutional neutrality. From a neutralist perspective, it did not much matter whether a governing board, speaking for a university, quarreled with an opinion by an expert or a nonexpert, or with an opinion voiced in a public arena or somewhere else: what mattered was that the board, on a mooted issue, had breached its social trust by compelling the institution to take sides.

Finally, the 1915 Declaration opened a new chapter in the history of academic tenure, by fitting it out with a new working plan, a series of concrete proposals concerning the acquisition and dispossession of tenure citizenship that, when refined and broadly adopted, would represent a very great reform. In this, too, the Declaration was more than a mere beginning but was a fount.

For an organization still in swaddling clothes, this polemical and analytical tour de force, magisterial in tone and yet plainspoken, at once familiar and original, was not only a gift it gave to a larger cause but an invaluable testimonial to its own precocity. One might suppose, therefore, that its leaders had an institutional interest in not rushing into a collaborative sequel that would compel it to share credit with outsiders and dim the luster of a bright debut. But, in fact, no sooner was the Declaration received by AAUP members with much self-applause than the leaders sought to use it as a scaffold for a joint venture with administrators, a follow-up that could be engineered only at the expense of infant vanity. Their reasons for doing so are instructive; they help explain why their followers in 1940 did not simply write what pleased them or bid for fame exclusively in their own words.

More than anything else, an unanticipated change in the planned activities of the association convinced its leaders during its natal year that going it alone would not carry them very far. In 1915, much to their surprise, Lovejoy, Seligman, and company were inundated by calls for help from faculty members on far-flung campuses who alleged that they were or were about to be dismissed because of their spoken or written views. Despite the empty 
treasury of the neonate association and their own chronic shortage of free time, this dutiful, unhappy few decided to respond to every seemingly meritorious SOS, not by taking the faculty member's complaint at face value, but by visiting the site of the proposed offense, nosing out the facts, interviewing all the parties, trying if possible to set things right, and then, if need be, exposing uncorrected wrongs. ${ }^{14}$

No program could have been better designed to reveal to the AAUP the disadvantages of being the sole source of support for the doctrines set forth in its Declaration. Even as they conducted their investigations, negative reviews of that work began to appear in conservative newspapers and administration journals. Much of the criticism was aimed at what was seen as its self-serving character. The editorial writers of the New York Times dismissed the professors' argument for professorial talkativeness and trustee reticence with a characteristic sneer: "'Academic freedom,' that is, the inalienable right of every college instructor to make a fool of himself and his college by . . . intemperate, sensational prattle about every subject under heaven ... and still keep on the payroll or be reft therefrom only by elaborate process, is cried to all the winds by the organized dons." 15 Others were more given to condemn it than deride it for its alleged one-sidedness. To the chancellor of Syracuse University, it seemed only fair that if professors were free to act on their "conscience and conviction," then trustees should be granted the freedom to fire them on their own conscientious and doctrinal grounds-a fairness doctrine that equated the right to express opinions with the right to banish them. ${ }^{16}$ And always in these organs someone could be counted on to make the worst accusation of bias-to call the document the manifesto of a professors' trade union, a description meant to be disparaging and regarded by the AAUP members of that period as demeaning. ${ }^{17}$ Still, it was one thing to encounter the ex parte argument when it appeared in journals of opinion, where it could not take immediate effect and could eventually be answered by a stinging letter to the editor, and another thing to confront it during a campus investigation, where it could serve to deny the AAUP access to the

14. See Walter P. Metzger, The First Investigation, 47 AAUP Bull 206 (1961); Walter P. Metzger, Origins of the Association: An Anniversary Address, 51 AAUP Bull 229 (1965).

15. Quotations: The Professors' Union, 3 School \& Soc'y 175 (1916), quoting the New York Times.

16. Is the College Professor a 'Hired Man'?, 51 Literary Digest 65 (1915).

17. See Lightner Witmer, The Nearing Case 68-69 (B.W. Huebsch, 1915) (reprinted with a new foreword, Da Capo Press, 1974), quoting The Professors' Union, a February 1914 editorial that appeared in the University of Pennsylvania Alumni Register. George Cram Cook, an academic socialist, berated "academic workers" for failing "to consider seriously the only line of action likely to lead to their independence .... The 'union' is capable of taking 'professor' out of the category of the ridiculous." George Cram Cook, The Third American Sex, 1 Forum 455 (1913). But Professor George A. Moore, the Harvard theologian who refused to associate himself with the new professorial organization because "[f] or the sake of a profession which I esteem I regret seeing it-pardon the word-unionized," gave expression to more typical sentiments. Letter, George A. Moore to Arthur O. Lovejoy (1915) (presented by Lovejoy to author in October 1960, and since merged with the files of the AAUP under the "Lovejoy 1915" heading). (This article cites repeatedly to archival documents in files possessed by the AAUP. All subsequent references to these materials will bear the notation "AAUP files.") 
administration, defeat AAUP efforts at mediation, and justify refusals to redress abuses cited in AAUP reports.

This peripatetic vanguard tried in a number of ways to secure a reputation for impartiality. One device employed by Lovejoy-to compose reports that would live up to the highest standards of judicial poise and objective scholarship - would serve as a model for later generations seeking to gain the confidence of both administrators and faculty members in divided houses. Another Lovejovian technique was to publish findings that did not vindicate the faculty complainant; for reasons rooted in the dynamics of a membership organization, this way of disowning the slogan, "my coprofessional right or wrong," did not set a lasting precedent. A third stratagem, which the visitation squads quickly saw the need for but which was beyond their power to effect, was to induce high-ranking and influential administrators to affix their seal of approval to doctrines that had become covered with professor fingerprints. Promising to rid the concepts of freedom and tenure of the taint of faculty class bias, while opening local rejectionists to the charge that they did not represent the sentiments of their own administrative class, this stratagem would appeal to every cohort of AAUP frontline caseworkers from that day to this.

The founding generation saw an added advantage in turning what started out as a solo enterprise into a joint one. In the spring of 1917, the new parttime secretary of the AAUP, H. W. Tyler, launched what became a long campaign to lure academic presidents to a conference that would endorse the spirit and main provisions of the 1915 Declaration in a formal statement. The crowning benefit of such a get-together and such a compact, according to this Massachusetts Institute of Technology professor of mathematics, would not be simply to strengthen the hand of the association when it answered the calls of faculty members in distress; even more significantly, it would reduce the number of occasions in which faculty members were likely to be distressed. "So far," he wrote, "we have been dealing with the individual institutions . . . If we have now reached the point where we can deal with a whole class of institutions at once, we may be in a position to win a campaign instead of a battle." 18 He was convinced that presidents in league with professors would do more to persuade governing boards to abide by proper policies than anything a small society of professors could do alone, and all the elected officers agreed that saving one institution at a time was a Sisyphean task that they hoped an entente with presidents could lift from AAUP shoulders. In later years, the institutionalization of case investigations and the increase in AAUP resources would take the edge off the latter reason for reaching out. No one in 1940 would have recommended a pact as a labor-saving device. But the belief that an act of legislated prevention was worth more than a pound of (often delayed, sometimes only marginally helpful) cure was shared by both leadership generations, as was the desire to devise a statement on

18. Letter, H. W. Tyler to Frank Thilly (March 26, 1917) (miscellaneous AAUP files). 
academic freedom and tenure that would be fit for framing in every academic board room. The two leadership generations had a further link in the person of Tyler, who would remain in office for eighteen years and would twice strive to make the foreign policy initiatives launched in the natal period bear fruit.

In one important respect, however, AAUP diplomatists in different times were taxed with different missions. When Tyler first broached the idea of a pact, representative groups of presidents and professors had never met to discuss professional issues on any stage wider than that of a particular campus, nor had the twain ever met, even at the local level, to agree on terms of employment through collective bargaining. Venturing into a void, the early leaders had to grope for answers to the most elementary questions. Who in the heterogeneous camp of college and university presidents would be suitable pact-partners? What items in the 1915 Declaration could be safely dropped or traded off, and what items should be deemed nonnegotiable? Whose drafted understanding of academic freedom and tenure should be used as the basis for discussion and be allowed to inform the final text?

By the time the next generation tried its hand, these questions had been answered for it. Its predecessor had identified the one presidential body willing to collaborate with the AAUP, had created an agenda for discussion that could be modified but not ignored, and had reached an agreement with the other side. This agreement, known as the Conference Statement of 1925, would be the going treaty for AAUP members who came late to this foreign service. Their task was not to write on an empty tablet; it was to revise what had already been written. Since they sought to amend, not replace, a coauthored work, the later leaders felt obliged to reopen negotiations with the same administrative body and not try to play the field. In short, where the first generation was awash with options, the second generation was pinned down by givens.

One can better understand what the AAUP of 1937-1940 was up to when one sees how the AAUP of 1915-1925 made up its mind. To the question of who should be invited to the parley, Tyler had a ready answer: he proposed that delegates from every national association of administrators should be invited in order to secure the broadest possible consensus. He did not fear that the AAUP would find itself in the overwhelmed minority in such a comeone, come-all assembly: "My expectation is that we should find the presidents as a class quite amenable to friendly treatment, and that those who might be otherwise inclined would be very much influenced by the collective action of their associates." 19 Tyler's sanguineness elicited a troubled response from colleagues that revealed a deep strain of antiadministration feeling in the AAUP's collective personality. Pointing out that none of the major administrative associations had embraced the 1915 Declaration and that one indeed had been strongly hostile to it, the president of the association, Cornell philosopher Frank Thilly, thought it more likely that "our friend, the

19. Id. 
enemy" would use the occasion to build "a solid front against us" than that it would respond to AAUP blandishments and break ranks. Lest the wisdom of the 1915 Declaration be trampled under by a hostile phalanx, he urged that the AAUP join hands with individual administrators, not associations, and, among individuals, only with proven friends. ${ }^{20}$

Among the founders, Thilly's antipresident animus did not rank as the most extreme. One of the earliest sponsors of a professorial association was the well-known Columbia psychologist, J. McKeen Cattell, whose chafing encounters with his own domineering president, Nicholas Murray Butler, had convinced him that the whole apparatus of presidential power should be dismantled, leaving a duumvirate of faculty members in control and lay boards in support, along the lines of the Oxbridge universities. Legally, in America, the governing board was the fountain of academic authority; historically, it had been the conduit through which pressures hostile to the faculty had been passed on to professors and sometimes amplified. Nevertheless, Cattell and the syndicalist faction that supported him lavished an invective on the deputy that they seldom visited on the source. ${ }^{21}$

Needless to say, if most of the early leaders had been of this persuasion, a pact with academic presidents would have been not just unpalatable but unthinkable. But most of Tyler's colleagues were (to borrow a phrase from English history) Whigs, not radicals: that is, they were protective, even though they could be highly critical, of the current monarchy (read presidency). As senior professors at major universities who were also preeminent figures in their respective disciplines, the founders had too-ready access to their own presidents to see them as devils incarnate and were themselves on too many short lists of candidates for presidencies to think well of abolishing that post. ${ }^{22}$ In the 1915 Declaration, it should be noted, they took aim at the transgressions of governing boards and ignored the managerial revolution that was shifting responsibility for personnel decisions from the legal governors of universities to their on-site agents. But if Whigs were not radicals, neither were they Tories, that is to say, loyal adherents to the party of the King. It was no accident that the AAUP was founded, not by the overworked and underpaid junior members of the profession, nor by their unrenowned seniors toiling away in the humblest places, but by an academic corps d'elite positioned in the cynosure institutions. Such professors were haughty enough to take affront at presidents who sought the deference due to royalty and secure enough to take on presidents who treated faculty criticism of their policy or person as a kind of lésè majesté. Nor was it an accident that the first self-defining act of the association was the passage of a constitutional provision declaring administrators ineligible for membership; this reflected a

20. Letter, Frank Thilly to H. W. Tyler, (March 31, 1917) (miscellaneous AAUP files); Letter, Frank Thilly to H. W. Tyler (April 7, 1917) (miscellaneous AAUP files).

21. James McKeen Cattell, University Control (Science Press, 1913).

22. See John Dewey, Faculty Share in University Control (with comments by Arthur O. Lovejoy) in Association of American Universities, Joumal of Proceedings and Addresses of the Seventeenth Anmual Conference 27 (Association of American Universities, 1915). 
deep professorial desire to create a professional space unconstrained by presidential presences. In Whiggish hands, pact-making would be burdened by the ambivalence of professors who sought out partners they were ready to look down on, who respected the presidential breed for being organizationally powerful but disdained it for being too often petty and tyrannical and intellectually second-class. These contradictory feelings, which for special reasons subsided in 1925, would rise up again in the second round when AAUP professors with a touchy professional amour-propre met a number of presidents they needed to win over but could not stand.

Tyler never abandoned his belief that "the more the merrier" was the right prescription for a treaty conference, and in 1925 he would go through the motions of acting on it. But the weight of leadership opinion did not subscribe to his motto, "blessed are the pactmakers, for to them all presidents are the children of God." The dominant view in the association fell between Thilly's and Tyler's. There was scant support for an invitation list so restricted that like would be sure to commune with like and no speaker would fear to be contradicted. At every parliamentary opportunity, the eminences grises, Lovejoy and Seligman, coaxed their colleagues into passing resolutions calling for "joint actions with other organizations." 23 If it were done "twere well it were done collectively-this was clear to those who measured the weight of a formal agreement reached by the emissaries of two estates and ratified by their respective governments against that of a harmonious exchange between like-minded people in one field of work who happened to occupy different posts. On the other hand, the word "other" did not imply the word "all." While many would have doubtless taken any organization's show of willingness to attend as strong proof that it deserved to be asked, most had a fairly clear idea of which presidential group, if it came, would be a godsend, and which, if it stayed away, would not be missed.

From all accounts, the early AAUP leaders, had they been forced to choose one and only one set of collaborators, would have picked the presidents of the elite research universities with major graduate schools, the institutions that belonged to the then exclusive Association of American Universities ("AAU"), formed around the turn of the century. Since these presidents were also their presidents, one might suspect that the "our crowd" mentality of the privileged was here at work. But in professor-president relations, closeness did not invariably make the heart grow fonder (as the founders' own frequent brushes with presidents over budgets and policies, prides and precedents, amply demonstrated). Something other than mere propinquity-something taken from recent academic history-seemed to have done more to color their affections. As a group, the AAU presidents had been prominently identified with the secularization of American higher education, a major wellspring of academic freedom on these shores. Although the first stirrings of hostility to

23. E. R. A. Seligman, Address of the President: Our Association-Its Aims and Its Accomplishments, 8 AAUP Bull 90, 108 (1922); Stenographic Record of Eighth Annual Meeting of the AAUP (1921) (AAUP files). 
sectarianism arose in the colonial colleges, and the first programmatic separation of college from church can be traced to the Jeffersonian era, the most dramatic victories of academic secularism were not scored until the latter part of the nineteenth century, when the presidents of certain old patrician colleges and the presidents of new establishments breathed into life by tycoon wealth labored to turn their institutions into universities comparable to Europe's research powerhouses. In 1915, AAUP memories did not have to stretch far back to recall that the architects of these transformations-the presidents of Harvard, Johns Hopkins, Chicago and the like-had been in the forefront of the battle to defend institutional neutrality against attempts by conservative religious forces to keep the Darwinian sciences at bay and to bar the critical study of the Bible. Clearly, the authors of the 1915 Declaration had in mind the attempts by antievolutionists and fundamentalists to institutionalize a godlier biology and a literalist interpretation of the Word when they dwelled on the functional necessity of free scientific inquiry within ideologically uncommitted universities. ${ }^{24}$ They quoted administrators sparingly, but they quoted with particular relish one titan recently retired from the Harvard-presidency who said that any governing board that would make "arbitrary" use of the dismissal power to "exclude from the teachings of the university unpopular or dangerous subjects" was-he used no softer word-“barbarous."'25 In these elevated quarters and on these well-defined topics, the AAUP could well believe that professors and presidents would indeed be friends.

In more recent years, to be sure, some doubts had arisen about whether the successors to the Charles W. Eliots, Andrew D. Whites, and Daniel C. Gilmans were as inclined to resist political and economic pressures as those worthies had been to withstand religious ones-the recent dismissal of the nonrevolutionary Marxist, Scott Nearing, from the Wharton School of the University of Pennsylvania was a worrisome investigated case in point. ${ }^{26}$ But there were grounds for optimism on this score as well. In 1916, A. Lawrence Lowell, Eliot's replacement as Harvard's president, made headlines by refusing to discipline a professor for his pro-German utterances, a refusal that threatened to cost the university the loss of a large bequest from an irate alumnus. ${ }^{27}$ Lowell's justification for restraint-a university that takes

24. The character of the contribution of the presidents of major universities to the secularization of American higher education in the latter part of the 19th century is suggested by the following: Andrew Dickson White, Autobiography (Century, 1905) (2 vols); Hugh Hawkins, Charles Eliot, University Reform, and Religious Faith in America, 1869-1909, $51 \mathrm{~J}$ Am Hist 191 (1964); Thomas Wakefield Goodspeed, A History of the University of Chicago: The First Quarter Century (Chicago, 1916); Winton U. Solberg, The Conflict Between Religion and Secularism at the University of Illinois, 1867-1894, 18 Am Q183 (1966); Daniel Coit Gilman, The Launching of a University (Dodd, Mead and Co., 1906).

25. 1915 Declaration at 23-24; Appendix $A$ at 395 (cited in note 13), quoting a 1907 address from Harvard president Charles William Eliot to the New York chapter of the Phi Beta Kappa Society.

26. Report of the Committee of Inquiry on the Case of Professor Scolt Nearing of the University of Pennsyluania, 2 AAUP Bull 127 (1916).

27. Abbott Lawrence Lowell, Annual Report to Harvard Corporation, 1916.17, quoted in Henry Aaron Yeomans, Abbott Lawrence Lowell, 1856-1943 311-12 (Harvard, 1948). 
responsibility for deciding what professors may not say thereby assumes responsibility for everything professors do say, and a wise university would refuse the first responsibility in order to relieve itself of the second-struck a blow for institutional neutrality that the AAUP would find very much to its liking. Thereafter it would argue in the Lowell manner that the tactic of mutual dissociation (the professor disavowing any claim to speak for the university, the university refusing to censor or condone what he says) is the proper way to enforce the neutral principle, the best means to the desired lack of corporate ends.

Whether AAU presidents were as likely to endorse the AAUP's position on academic tenure as they were on academic freedom was probably regarded as a more open question. But the 1915 Declaration did suggest that the same institutional characteristics that made academic freedom a functional necessity were likely to make academic tenure an operative reality. While its authors hoped to establish their kind of tenure system everywhere, they made it clear that the AAU universities, large enough to maintain an array of specialties beyond the ken of lay and administrative nonspecialists, sophisticated enough not to stand petty watch over speech in the lecture hall and classroom, and ambitious enough to encourage the faculty to live a double life wedded both to their science and their university, provided the best available environment for healthy tenure practices and was thus a training school for potential pactpartners sans pareil.

The initial affinity of the early AAUP leaders toward one administrative association was matched by their initial antipathy toward another. Left to their own preferences, the AAUP leaders would not have chosen to treat with the presidents of denominational colleges, whose very existence posed a challenge to the neutral principle; nor with the presidents of small undergraduate colleges with very sheltered student bodies, whose regimen more closely resembled the supervisory strictness of a school than the strategic leniency of a university; nor with the presidents of low-level traditional liberal arts colleges, where the curriculum was too abecedarian and faculty members too often jacks-of-all-trades to give laymen much opportunity to honor academic expertise. Since institutions of these sorts were then conspicuous in the Association of American Colleges, that organization was at once perceived by leading members of the AAUP as the home of some of its worst natural enemies: the clerical president who administered doctrinal tests to incoming or resident faculty; the patriarchal president who treated faculty members as sojourners in his house who were expected to resign whenever he determined they should go; the provincial president who knew little of matters beyond his teacup world.

The AAUP's negative impression of the AAC was strongly colored by an article that appeared in the AAC Bulletin two years after its founding. In 1917, its newly formed Committee on Academic Freedom and Tenure of Office, set up as a counterfoil to Committee $A$ and composed mainly of presidents of religious colleges, issued an extensive review of the 1915 Declaration that was 
thoroughly out of sympathy with its arguments and alarmingly out of touch with the norms of accurate reportage. Not at all unwilling to place faculty members at the mercy of vague creedal requirements and an inquisitional spirit, the AAC committee asserted that "[a] man who accepts a position in a college which he has reason to believe is a Christian institution" may not claim under academic freedom "the right privately to undermine or publicly to attack Christianity," even if the behavioral or confessional demands of the institution had not been specified prior to appointment. With regard to academic tenure, the Committee opined that the key question raised by the 1915 Declaration was whether "any association of university professors [should be allowed to] compel a corporation to retain in office for an indefinite time one who is manifestly unfit for that particular place." No one acquainted with the 1915 Declaration solely through this misreading of it would suspect that it proposed not to maintain the manifestly unfit but to make unfitness manifest through certain probative procedures. Finally, the committee could not resist inveighing against the "mischief-makers," "vexels," and "impossible persons" on the faculty who were tolerated by trustees and would be cashiered by any "well-organized corporation." 28 It was this obtusely hostile review that led Thilly to estimate the chances of the AAUP prevailing over a melange of presidents to be about as good as those of the early Christians emerging triumphant from the lions' pit. It prompted even the tolerant Tyler to remark that the AAC institutions were "the very ones which, on account of their size and local quality, were most in need of reform" and to predict that they would be slow "to accept a progressive policy in advance of the large institutions in the Association of American Universities." 29

To paraphrase a Scottish poet, the best-laid schemes of mice and academic men gang aft agley. The AAUP sought out the AAU, but the AAU did not reciprocate. The journal of the AAU took no notice of the 1915 Declaration; an AAUP questionnaire on items in that report sent out to AAU presidents elicited few replies; the staff of the AAU did not warm to Tyler's approaches. Its unresponsiveness may have been due to a number of factors: to its preoccupation with graduate education and other concerns of the disciplinary professions not directly implicated in current academic freedom and tenure issues; to its belief that among its constituent members academic freedom was a paradise already gained and that tenure held no advantage over informal gentlemen's agreements; or-perhaps this was the most potent reason-to its perception that as the oldest and most Brahmanic of administrative associations, it would not add to its dignity or repute by hobnobbing with a newly-arrived, untested association of professors drawn in all likelihood from the malcontents on the faculties of the very institutions it served. By contrast, the AAC took the pronouncements of the organized professors very seriously,

28. Committee on Academic Freedom and Tenure of Office, Report of Committee, 3 AAC Bull 49. 55 (April 1917) ("AAC Repori").

29. Letter, H. W. Tyler to Frank Thilly (April 3, 1917) (miscellaneous AAUP files). 
witness the speed with which it set up a committee to deal on a parallel, if not equal, footing with the formidable Committee $\mathrm{A}$ and the space it devoted in its Bulletin to a rebuttal of the latter's work. Moreover, even in blustery opposition, its freedom and tenure committee paid oblique tribute to the professors from Johns Hopkins, Columbia, and Wisconsin by referring to them as "excellent men in responsible positions" 30 who were somehow offering bad advice, and by treating the 1915 Declaration as an encyclical that had to be solemnly refuted before it could be comfortably defied. The probable explanation for this attitude is that the AAC, as the sole administrative organization that concentrated on the cross-disciplinary problems of college teaching, was especially sensitive to the views of the sole ecumenical association of college teachers. Also, by virtue of the fact that it was as parvenu as the AAUP and a lot less snobbish than the AAU, the AAC probably regarded dialogue with well-placed professors, even if hostile, as a way of moving up, not stepping down. From these early signs, a clever prognosticator would have bet that the AAUP would eventually get not the pact-partner it wanted, but the pact-partner that wanted it.

That required foresight: for some years the leaders of the AAUP lived with the disquieting thought that they might not find any pact-partner at all. Certainly, as long as they bristled at the AAC's adverse review, they would not be cheered by the flattery of its attentiveness. But then the AAC changed its mind, or, rather, changed the membership of the Freedom and Tenure Committee, and the reconstituted committee changed its mind. In 1922, that committee issued a second report that in effect repudiated the first one. It described the 1915 Declaration as "highly important" (its new chairman called it "monumental"). ${ }^{31}$ It urged all colleges and universities to safeguard academic freedom, which included recognition by the institution that a faculty member in speaking and writing upon subjects beyond the scope of his own field of study is entitled to the same freedom and responsibility as attached to all other citizens. It endorsed the principle of tenure to the extent of urging that faculty members who had demonstrated their competence and compatibility to the satisfaction of the institution should receive a long-term or indefinite appointment, and that the termination of such an appointment for cause should be preceded by a hearing on charges. It held that religious colleges could require faculty members to adhere to creeds but distanced itself from its precursor by insisting that such requirements be made known to candidates for positions before they sign on. It introduced a number of exceptions and qualifications into its statement that sapped the protective strength of a number of provisions in the AAUP Declaration, but it displayed none of the sodden animus that had defaced the committee's review of that document five years before. ${ }^{32}$

30. AAC Report at 49 (cited in note 28).

31. Association of American Colleges, Record of Annual Meeting 79 (1922).

32. Charles N. Cole, Report of the Commission on Academic Freedom and Academic Temure, 8 AAC Bull 94-103 (March 1922). 
This rejection of the antagonistic past was the work of Dean Charles $\mathrm{N}$. Cole of Oberlin College, who along with the distinguished educational historian, Charles F. Thwing, president of Western Reserve University, and Dean Roy C. Flickinger of Northwestern University, had replaced presidents of church-related colleges on the committee and had altered its temperamental and ideological balance. The committee turnover signalled that the AAC, which had started out as a meeting-ground for the heads of the smallest and most parochial private colleges in the country, had begun to gather in the presidents (and, importantly, the deans) both of private liberal arts colleges with regional and national reputations and of sizeable private universities with strong undergraduate divisions-a small but growing and influential minority of personalities of secular bent and broad horizons. And the policy turnabout suggested that cosmopolitan AAC presidents might have more in common with cosmopolitan AAUP professors than they had with provincial AAC presidents, and that an interorganizational alliance might well be built on this break in executive ranks.

These were indeed glad tidings to the officers and secretary of the AAUP, who had gone through the years of unwanted isolation with increasing pessimism. It did not take long for them to perceive that formal collaboration was a possible outcome of improved rapport. ${ }^{33}$ But it did take some time before habitual mistrust yielded to unaccustomed friendliness. The AAUP had reasons to be wary: the old guard was still ensconced in the governing councils of the AAC; the new guard failed by a long shot to endorse the whole 1915 Declaration. The reborn AAC also had grounds for cautiousness, not least of which was the danger that a meeting with the AAUP, following upon its endorsement of what were thought to be pro-AAUP sentiments, would not sit well with members to whom that very acronym was a provocation. Gradually, each side assured the other that it had much to gain and nothing to lose from a detente. At the 1923 annual meeting of the AAC, Dean Cole delivered a ringing defense of academic tenure (far from protecting "all college teachers not disqualified by gross misconduct," it is "a policy by which teachers of tested competence, character and loyalty are lifted above the plane of annual, biennial or quinquennial appointments and put into the position of trusted partner appointed without term"), ${ }^{34}$ and thereby indicated that a joint conference would not waste its time debating AAUP first principles. For its part, the AAUP let it be known through the chairman of Committee A, Professor H. F. Goodrich of the University of Michigan Law School, who met with Cole at Ann Arbor to resolve outstanding differences, that it would be willing to accept the 1922 report, with minor amendments, as a preliminary draft and basis for discussion, and would not press for the Seligman moon if

33. Executive Comittee Actions, May 26, 1923 (AAUP files); H. F. Goodrich, Annual Report of Committee $A, 10$ AAUP Bull 71, 74-75 (1924).

34. Charles N. Cole, Report of the Commission on Academic Freedom and Academic Tenure, in 1923 AAC Proc 127-28 (1923). 
that was likely to produce an unratifiable document. ${ }^{35}$ Finally, as a historian of diplomacy might put it, they had taken enough confidence-building steps to agree on the date of a summit meeting.

In the historical preface to the 1925 Conference Statement, it is recorded that the American Council on Education ("ACE"), a coordinating agency for higher education established in 1918, invited the AAUP, the AAC, the AAU, the Association of Governing Boards, the Association of Land Grant Colleges, the Association of Urban Universities, the National Association of State Universities, and the American Association of University Women to a conference in Washington from which a succinct collective agreement on the principles of academic freedom and tenure emerged. ${ }^{36}$ The facts are correct, but this way of recounting them hides the truth.

The idea of gathering under one umbrella so large a part of the infinite variety of American higher education was the brainchild of $\mathrm{H}$. W. Tyler, who had remained wedded to the hope that such an assembly, like a league of nations, would covenant to abide by a common code, and who found a way at last to act on that hope when, as the AAUP's representative on the ACE, he succeeded to its rotating presidency. The council resolution he put forward authorized the issuance of invitations only when the AAUP and the AAC decided that the time was ripe for it, a proviso that left no doubt about who was really throwing the party. The conference, which lasted no more than one full day, made few changes other than stylistic ones in the distributed draft, and those changes were not of large importance. ${ }^{37}$ The discussion was lively, but it was kept within bounds by Tyler, who chaired the conference. Once, when the representatives of the women's association raised such questions as whether good teaching could be objectively measured or productive scholarship clearly assessed, he shunted those hardy perennials of academic discourse to a subcommittee, which never reported. Given the provenance and management of this affair, it was hardly surprising that only the AAC and the AAUP took pains to adopt the final statement. ${ }^{38}$ The second

35. Memorandum of Charles N. Cole and H. F. Goodrich (April 9, 1924) (Committee A memoranda, AAUP files).

36. Principles and Proceedings Governing Academic Freedom and Tenure, 18 AAUP Bull 329 (1932).

37. 1925 Conference Records (AAUP files).

38. The Conference Statement did not have easy sailing through the governing bodies of the AAUP. To answer criticisms, Tyler and others promised that a second conference would soon be held to rectify the defects of the first conference statement, but refused to risk sending the document to the local chapters for their approval. Letter, H. W. Tyler to AAUP President, A. O. Leuschner (January 31, 1925) (1925 Conference folder and Council Letters 1925-26 folder, AAUP files); letter, H. W. Tyler to A. O. Leuschner (May 6, 1925) (1925 Conference folder and Council letters 1925-26 folder, AAUP files). At the 1926 annual meeting of the association, the delegates expressed their "general approval" of the 1925 Statement, but added that "[i]t is understood that the [provisions of the 1925 Statement] are to be interpreted as far as this Association is concerned in the light of its previous declarations on academic freedom and tenure . . ." Record of Annual Meeting of 1926 (AAUP files). Lovejoy headed off the possibility of an outright rejection by reminding the members that the AAUP did not start from a "clear field" but from a document already adopted by the AAC and that the AAUP team had decided to agree "not necessarily to all that might be desired but a minimum standard sensibly in advance of what is as yet generally accepted by the administrative authorities of American colleges." Id. The AAC adopted the 1925 Statement handily, recognizing it 
Treaty of Washington, unlike the first (and slightly more famous!) conference of that decade on international naval disarmament, did not concert the views of all the major powers. It was an AAC-AAUP affair through and through, and the others were merely extras placed in seats to lend the mise en scène an air of fullness. A decade later, when the prime movers of the 1925 conference decided that the pact had serious flaws and should be revised, neither suggested that the various groups once assembled in Washington should be brought together again. Neither saw any point in repeating what had been mostly a charade.

What difference did it make that the 1940 Statement was the result of a second try at pact-making by the AAUP and AAC, and not a product of the AAUP alone? The difference can be roughly measured by comparing the AAUP's unalloyed work in 1915 with the co-authored statements that came after, taking due account of the changes the 1915 Declaration might have undergone if its single parent had tried to bring it up to date. For orderly analysis, it may help to distinguish differences attributable to the period in which these works were written ("signs of the times") from those attributable to differences that would have appeared in any period ("genre effects"). Further, where the aria and the two duets disagree, it may be helpful to distinguish disagreements based on discrepant omissions ("agenda gaps") from disagreements resulting in head-on collisions ("confrontations"). Finally, it may pay to speculate on what might have happened if the AAUP had found a different pact-partner ("what if?"). Two caveats: (1) the uncovering of discrepancies between AAC and AAUP positions should not obscure their large area of concurrence; (2) it should not be automatically assumed that whatever is clever, useful, or prescient in the 1940 Statement was put there by the professors, and that everything flat, unprofitable, and regressive is there because the presidents could not be moved.

\section{A. Signs of the Times}

Neither the AAC nor the AAUP ever sought to compose an exhaustive, detailed list of the shortcomings and misbehaviors that would give an academic institution sufficient cause to dismiss a faculty member. The presidents' group declined to do so out of deference to the diversity and desired autonomy of institutions; for the same reason they tried to avoid mandating a uniform dismissal procedure. The AAUP did not hesitate to impose uniform procedures on that disorder Americans were pleased to call a system of higher education. But it did share the substantive shyness of the AAC: except insofar as it agreed that an infraction of an etiquette of public speech were institutionally punishable ${ }^{39}$ it consistently refused to itemize the

as, for the most part, the handiwork of its own committee. Association of American Colleges, 1925 Records of Annual Meeting. A few years later, however, the presidents of small colleges would also begin to voice strong opposition to the 1925 Statement.

39. See generally Part IIE. 
grounds on which professors might be dismissed. Its primary reason was that a "criminal code" approach, as it came to be called, could lead to the proscription of so many specific actions, and applied with so much literalness, that little room would be left to judge the motives of the affected teacher or to take into account in the final reckoning his professional record as a whole. For different reasons, the two associations agreed to employ an inexplicit phrase of art-"professional unfitness"-to serve as the quod erat demonstrandum of a dismissal hearing, and to leave to local experience the definition of which particular falls from grace merited condign punishment.

Still, if the AAUP took a firm stand against a precise and exhaustive specification, it did manage in the 1915 Declaration to identify in general terms a few charged offenses that justified a dismissal hearing and a few verdicts that merited dismissal without notice. These en passant references to "what" on the way to a more thoroughgoing consideration of "how" set the precedent for a similar kind of indirect and partial enumeration of punishable offenses in the first president-professor pact. In 1915, the AAUP had alluded to "habitual neglect of assigned duties," "grave moral delinquency," and "professional incompetence" as valid grounds for terminating the appointment of a tenured professor. In 1925, the AAUP and the AAC, in the same by-the-way manner, mentioned, as before, "professional incompetence" and "gross immorality," but added a new capital offense-" treason." The last offense was regarded as so egregious that, along with "immorality," it could, merely by being charged, result in a summary dismissal if the facts were not in dispute.

As soon as he read the document, the distinguished first President of the AAUP expressed a grave concern. John Dewey let Tyler and Lovejoy know that he found the acknowledged possibility of a dismissal for treason both gratuitous and dangerous. "If a person were convicted of treason, naturally the connection with the university would cease, as it would were he convicted by the courts of any other crime." But if treason were given a popular interpretation, the charge of this offense "might be employed in cases similar to those arising during the late war to justify the dismissal of teachers whose views on national policy were contrary to the patriotic sentiments of the time." For once, Lovejoy, who had been at the Washington conference as a member of the AAUP's four-man delegation and had been as usual the dominating intellectual force among his peers, seemed defensive, if not abashed. He had not fought to strike the troubling word, he told his philosophical colleague, "because it had occurred in the resolutions of the Association of American Colleges . . . and because the representative of that Association feared ... he would have great difficulty in getting the revision approved at the meeting of that body ... if the word had been cut." He would have preferred to see the word omitted, but only "if this could be done without sacrifice to the rest of the agreement, which as a whole seems to constitute a great advance." Tyler also recalled that the decision to let "treason" stand, though opposed by other participants as incautious, was 
made in deference to a higher prudence-in order to appease a governing body made up of presidents with fixed ideas.

There was more to it than that. The conference minutes, though sparse, do not suggest that this issue received long or hot discussion, and the retrospective statements of the conference members do not suggest that they had swallowed a bitter pill. Tyler was nonchalant: he thought the word "would probably do no real harm," though he did not say why he doubted that those who cried "treason" would make the most of it. Lovejoy was argumentative; he tried to convince Dewey that there was nothing to fear, first, because the members at the conference all agreed that the term should be interpreted in a strictly legal sense, and, second, because if it were interpreted in such a way as to force out a mere political dissenter, the teacher "would have very good grounds for a damage suit."40 These arguments were not worthy of that forensic master: "treason," however understood by the discussants, was not defined in the document and thus could be anything in the eye of an uninformed beholder; playing with fire is hardly made more safe by the hope that burns will be compensated later on. A plausible explanation for Lovejoy's weak retort is that, unlike his recovered peer, he had not yet regained the robust libertarianism that had deserted him during the Wilsonian "Great Crusade," 4 I and that, when national loyalty was at issue, the lingering symptoms of war psychology, dovetailing with a desire not to rock the conference boat, kept him from acting at his semantic best. And if in the mid-1920s Lovejoy still needed more time to recuperate from the illness of superpatriotism, it is likely that many presidents other than those who belonged to the AAC, and many members of the AAUP apart from its principal founder, had at least as far to go.

In the years that immediately followed, treason was seldom if ever charged against a faculty member to effect a dismissal, doubtless because faculty members could be dismissed more expeditiously by stretching the elastic in "immorality" and "incompetence." But the reference to "treason" in the first AAC-AAUP pact would become increasingly objectionable to professors and administrators alike, especially in the New Deal period when the campus mood grew conspicuously less conservative and when the House UnAmerican Activities Committee began to give the pursuit of subversives a bad name. More than the weightier matters that drove the AAUP and the AAC back to the conference room, this oddity, which became an eyesore, served as a constant reminder of the need to revise the 1925 Statement, and the revisionists of 1940 would agree to expunge it before they agreed on anything else.

40. Letter, John Dewey to H. W. Tyler (April 1, 1925); Letter, A. O. Lovejoy to John Dewey (April 13, 1925); Letter, H. W. Tyler to John Dewey (April 7, 1925) (all in 1925 Conference folder, AAUP files).

41. See A. O. Lovejoy, Edward Capps, \& A. A. Young, Report of Committee on Academic Freedom in Wartime, 4 AAUP Bull 29 (February-March 1918) (report mostly written by A. O. Lovejoy). 


\section{B. Genre Effects}

The literary goal of AAUP-AAC collaboration was to reduce the complexities of academic freedom and tenure to a capsule statement that could be read at a glance, be readily understood, and be acted on with despatch. Accordingly, the collaborators sacrificed explanation to synopsis and leisurely argument to dicta tightly phrased. Accordingly, too, most of the philosophy of the 1915 Declaration was parked outside the 1925 and 1940 Statements, as were all the images and turns of phrase for which the draftsmen could find no succinct equivalents. What are here called "genre effects" are the substantive differences between single-authored and doubleauthored words that can be laid not to conflicts in collaboration but to the sheer need to epitomize.

Chief among the ideas lost in compression was the norm of institutional neutrality, the keystone in the AAUP's primal theory of academic freedom. Faint traces of that norm can be found in the 1925 Statement by a reader willing to endure the eyestrain of detecting traces. For example, the academic freedom section alluded to what institutions may not do, not to what faculty members may do; instead of offering three helpings of largesse, the administrative signatories of this document agreed to three self-denying ordinances. Another trace of the neutral norm can be found in the 1925 wording of the Lowell principle. Faculty members were admonished "to take pains, when necessary, to make it clear that they are expressing their own views, and not those of the institution" because it had to be "clearly understood that an institution assumes no responsibility for views expressed by means of its staff." By 1940, even these weak residues of 1915 had disappeared. Uncomfortable with the Seligman façon de parler, the authors of the 1940 Statement elected to put the case for academic freedom in a positive, not a negative, fashion: ergo, they spoke of faculty entitlements instead of institutional forbidances. In addition, they gave up the idea that dissociation was an institutional desideratum and thus converted the rump statement-a faculty member "should make every effort to indicate that he is not an institutional spokesman"-into little more than a plea for good public manners.

Finding no phrase that explicitly upholds the essentiality of the neutral norm, the wielders of the 1940 Statement have been spared the difficult task of drawing lines between permissible and impermissible institutional partisanship. They have not been called upon, for example, to distinguish an educationally neutral institutional policy (not necessarily desirable and arguably impossible) from a politically neutral institutional policy (arguably always possible and even imperative). Nor have they been required to draw distinctions between regulations regarding the time, place, and manner of free expression, which minister to institutional convenience and play no favorites, and regulations that are demonstrably discriminatory in intention or effect. Had it been studded into the text, the demand that the academic corporate body be unopinionated might well have over-taxed the interpretive 
and operational skills of Committee A. But out of sight has a way of becoming out of mind, and code-enforcers have paid a price for not remembering what the essayistic first generation wrote and later epitomizers failed to capture. Their amnesia has doomed the 1940 Statement to irrelevance on a host of lively academic freedom issues, ranging from academic investment decisions made under ideological pressure to the ideological biasing of departments through patterns of appointment that shut out significant schools of thought. ${ }^{42}$

This nonremembrance of things past has played havoc with attempts by the AAUP and others to grapple effectively with the "limitations clause," the only provision in the 1940 Statement that touches on the compatibility of individual academic freedom with institutional religious or other doctrinal tests. The words of this provision come from an every-day vocabulary"limitations of academic freedom because of religious or other aims of the institution should be clearly stated in writing at the time of the appointment"-but they vibrate with mystery and ambiguity when read without the 1915 master key. ${ }^{43}$

For all their deep-seated secularity, the authors of the 1915 Declaration did not challenge the right of a religious college to exist. Nor did they undertake to rid the academy of all religious tests. Why were they so permissive where, in the light of neutralist theory, it might be expected that they would be stern? In part, discretion dictated forbearance. The pluralist tradition in religion, sanctioned by centuries of American experience, argued not only for freedom of worship but for freedom to proselytize as well; the laissez faire tradition in education, secured by the constitutional immunization of private colleges from state encroachments, protected the proselytical college and permitted enrollments in mundane subjects in those colleges to count for conventional academic degrees. Not contesting the right of an academic institution to indoctrinate students in its sponsor's faith, the founders felt that they could hardly contest its right to make adherence to that

42. The campus turmoils of the 1960 s set loose a wave of fresh analyses of the norm of institutional neutrality. Neutrality or Partisanship: A Dilemma of Academic Institutions, 34 Bulletin of the Carnegie Endowment for the Advancement of Teaching (1971); Alan Montefiore, ed, Neutrality and Impartiality: The University and Political Commitment (Cambridge, 1975). From that time on, the interest of American academics in the issue of academic neutrality has not lacked for controversies on which to feed. See Derek Bok, Beyond the Ivory Tower (Harvard, 1982); W. Todd Furniss and David Gardner, eds, Higher Education and Government: An Uneasy Alliance (American Council on Education, 1979); Alan Pifer, Beyond Divestment-The Moral Liniversity, 38 AAHE Bull 3 (May 1986). One indication of how distant the AAUP has been from this concern is that not one of the forty-six statements it promulgated either alone or with others between 1963 and 1990 so much as touches on it. See generally 1990 AAUP Red Book (cited in note 1). Only recently, with regard to the persistently troubling "limitations clause," has the norm of institutional neutrality made a significant reappearance in an AAUP journal. Matthew W. Finkin, et al, The Limitations Clause of the $19+0$ Statement of Principles, 75 Academe 52 (September-October, 1988).

43. In 1967, an AAUP committee set up to re-examine the limitations clause referred to the 1915 assertion that restrictions on the academic freedom of professors were incompatible with academic freedom. It concluded, however, that the 1940 agreement allowed it to improve on the application of these restrictions but otherwise tied its hands. Report of the Special Committee on Academic Freedom in Church-Related Colleges and Universities, 53 AAUP Bull 369 (Winter 1967). 
faith a condition of membership in its faculty. Perhaps if the major universities founded by churches, such as Harvard and Chicago, or the distinguished colleges established by sects, such as Amherst and Carleton, had continued to catechize their faculties, the AAUP would have felt obliged to launch a frontal attack on this classic form of institutional non-neutrality. But in 1915, although the academic landscape was filled with small denominational and Catholic colleges, almost every academic institution of wealth and consequence had relinquished any confessional requirement they had ever had, and it seemed that the quest for endowments and reputation, not to mention the appetites stirred by the pension gifts offered to nondenominational colleges by the Carnegie Foundation for Teaching, would lead the great bulk of the lagging institutions to follow suit. There seemed to be no need to tilt at formidable traditions when the historical trend and all the high examples seemed perfectly able to do the trick.

But in 1915 the AAUP would not countenance an attempt by an academic "instrument of propaganda" (in whatever cause, be it for socialism, the protective tariff, or religious dogma) to parade itself as a home for academic freedom or call itself a true college or university. "Concerning the desirability of the existence of such institutions, the committee does not desire to express any opinion. But it is manifestly important that they should not be permitted to sail under false colors." Honest advertising was the obvious program for institutional neutralists who viewed religious tests as the enemy of academic freedom but did not want to be dictatorial or quixotic in opposing them.

To cut down on the deceptive use of religious tests, the authors of the 1915 Declaration insisted that all institutions of a sectarian or partisan character should make this fact known to candidates for academic positions before clinching their appointments. The timing of this disclosure struck the AAUP as important for several reasons. Applied before the bargain was struck, a religious test would give applicants the information they needed to make an informed career decision; divulged afterwards, it could take unsuspecting faculty members by surprise. Furthermore, the young AAUP supposed that a precursive religious test would help the college define its true character not only to the job-seeker, but to the public, the profession, and perhaps itself. Conversely, it assumed that the posterior religious test, applied within the sanctum of a college, would serve such nefarious purposes as helping one religious faction seize control of the institution from another or give a president an excuse for ousting an otherwise entrenched faculty foe. ${ }^{44}$ The AAUP had not said, however, that a forerunning religious test was

44. One early case, predating the formation of the AAUP, was investigated and reported by Lovejoy and a small committee on behalf of several disciplinary societies. Case of Professor Mecklin, Report of the Commitlee of Inquiry of the American Philosophical Association and the American Psychological Association, $11 \mathrm{~J}$ Phil, Psych \& Sci Method 67 (1914) (case of Mecklin and Lafayette College). For some early AAUPers, the dismissal of Willard Fisher from Wesleyan University on vaguely religious grounds pointed to the danger of letting administrators hide a disreputable reason for dismissing a teacher in a presumably more reputable creedal bunker improvised for the occasion. "Willard Fisher Case" folder (1915) (AAUP files) (donated by Donald L. Kemmerer); "Fetter Draft of Report on 
tantamount to no religious test. When the AAC first offered its opinion on this subject in 1917, it had defended the appropriateness of all religious tests, whether administered before or after an appointment. When it spoke in 1922 for the second time, it took the position that an academic institution has every right to prescribe an orthodoxy, but that it may not, consistent with academic freedom, do so ex post facto. In the glow of the rapprochement, the AAUP welcomed this much accommodation to the neutral principle and did not press the point that, while it found some religious tests more palatable than others, it regarded all religious tests as inimical to academic freedom.

The 1925 Statement recorded the AAC's second thoughts, not the AAUP's first thoughts, on this subject:

A university or college may not impose any limitation upon the teacher's freedom in the exposition of his own subject in the classroom or in addresses and publications outside the college, except in so far as the necessity of adapting instruction to the needs of immature students, or in the case of institutions of a denominational or partisan character, specific stipulations in advance, duly understood and accepted by both parties, limit the scope and character of instruction. ${ }^{45}$

Hardly deserving of a prize for literary clarity, this convoluted sentence could be reconstrued as follows: (1) provided it makes its doctrinal demands crystal clear in the original terms of employment, an academic institution may impose such demands with the permission of the AAC and the AAUP; (2) once they agree to adhere to doctrinal demands that have been nominated in the bond, faculty members who later change their minds, and are on that account dismissed, can expect no succor from the AAC or the AAUP; (3) although the end of the sentence speaks of limits only on instruction, the beginning speaks of limits on outside publications and addresses too, and so it may be supposed that the institution is allowed to discover a punishable apostasy in every mode of expression; (4) denominational or other partisan institutions that obey this prescription for open dealings are not violating the rules of academic freedom, but are rather qualifying for a narrow exemption provided for under those rules; hence, they may claim to have academic freedom when they limit it only in these sanctioned ways. Yet more concisely: there is nothing wrong with an opportune religious (or other doctrinal) academic test.

In the course of the next decade, the AAUP had an opportunity to learn from field experience that an antecedent religious test was filled with defects. For one thing, no religious test, early or late, was likely to be confined to specific articles of belief. In a Protestant milieu, where theology tended to dissolve into piety, a dogmatic core was hard to isolate; in a Catholic milieu, where matters of faith were authoritatively decided, so too were matters of morals, and the two were authoritatively intertwined. The AAUP saw great

Fisher Case" (1915) (donated by Frank W. Fetter) (AAUP files); Summary Report of the Commiltee on Academic Freedom and Academic Tenure on the Case of Willard C. Fisher of Wesleyan University, 2 AAUP Bull 119 (1916).

45. AAUP, 1925 Statement of Principles on Academic Freedom and Tenure, 18 AAUP Bull 329 (1932) ("1925 Statement"). 
dangers to personal freedom in this interlinking of creed with conduct. Religious communities often failed to distinguish the spiritually essential from the culturally familiar; behaviors deemed innocuous in some religious settings, such as dancing, drinking, or marrying someone who had been divorced, could be seen in another as steeped in sin.46 When the AAUP tried to draw a line between valid doctrinal demands and invalid behaviorial coercions, it appeared to set itself up as the arbiter of true religion, which was an awkward presumption, to say the least. For another thing, the leadership of religious colleges all too often lacked the stability and continuity necessary to make preappointment promises binding. Two kinds of academic institutions were likely to administer tardy religious tests; those torn by internal conflicts within the parent church, and those shuttlecocking between past and present, appealing to new nonreligious constituencies while trying to hold on to older religious ones. Divided and traditional religious colleges grew faster than had been predicted in 1915 , so that it seemed that before the 1925 Statement could ameliorate the problem of religious tests, historical trends were likely to exacerbate it.

If anyone on the AAUP negotiating team burned to rewrite the 1925 passage on religious tests in order to reclaim institutional neutrality as a root idea, this desire escaped the recorders of the 1940 negotiations. Pact-writers on a second round have a natural reluctance to open up settled issues to fresh debate; the adage about not stirring up sleeping dogs has a special relevance for workers in this genre. For the second round, the AAUP and the AAC came in with drastically altered texts on only a few topics, and the topic of religious tests was not one of them. To prepare the ground for their conference with the presidents, the AAUP asked its legal counsel, John $\mathbf{M}$. Maguire of the Harvard Law School, to improve on the first agreement, the inescapable starting point for discussion. Treating this more as a rewording than a rethinking assignment, Maguire split the overpacked sentence into its component parts, shifted all but one part to other regions of the text, eliminated the cumbersome syntax of what remained, and emerged with what, after some amendment, would come to be known as the "limitations clause." 47

46. The Bethany College-Croyle case, Committee on Academic Freedom and Academic Tenure, Report of Enquiry into Conditions at Bethany College, 5 AAUP Bull 26 (May 1919) (case of H. I. Croyle), was the key case from a religious college before 1925. In it the AAUP was unable to decide whether the professor had been fired because he taught the Bible from "the modern point of view" or because he flouted social conventions. Similar uncertainties afflicted treated but unreported religious college cases before the pact. Case file, Mercer College-Fox (1924) (AAUP files); Case file, Missouri Wesleyan-Reed (1925) (AAUP files). The 1925 distinction between acceptable and unacceptable religious tests was not of much help to the AAUP. What was murky about the proper grounds for dismissal from a religious college before 1925 did not become clearer afterwards. Some administrators of religious colleges would take advantage of the religious exemption to effect a quite secular end, such as ridding themselves of professors who were thorns to them personally. See Academic Freedom and Tenure, Committee A, Report of the Sub-Committee of Inquiry for William Jewell College, 16 AAUP Bull 226 (1930) (case of Ryland Fleet).

47. The heavy flow of religious college cases coming to AAUP attention after 1940 as a result of changes within Protestant and Catholic higher education gave the limitations clause a salience to 
In some respects, Maguire editorialized more aggressively than he had planned and came closer to the AAUP's original intent than he knew. He indicated in his stripped-down sentence that any expressional constraint due to an institution's "religious or other aims" was indeed a "limitation of academic freedom" and remained such even if it took the better of several possible forms. He uncoupled the reference to religious tests from the reference to teaching technique, thereby avoiding the suggestion that a demand for intellectual conformity on the part of mature adults and the protection of the sensibilities of callow youth were much alike. He inserted the requirement that institutional limitations on free speech should be clearly stated "in writing" (the 1925 Statement had merely asked for a clear bilateral "understanding"); this reflected a growing awareness that oral agreements are notorious breeders of misunderstandings, and that intramural conflict can be resolved more readily when documents, rather than merely memories, are used to evaluate conflicting testimony. Finally, by altering the format of the sentences to avoid stating a prohibition followed by an allowable exception, he did something to escape the inference that the AAUP and the AAC had gotten into the business of issuing indulgences to religious colleges provided they were careful about when they showed their stripes.

But without the arguments for institutional neutrality to light his way, the drafter of the limitations clause did not do enough. Reshuffling words without adding explanations (the compressed genre did not admit of explanations), he still left many readers with the impression that academic freedom and religious tests could reach a modus vivendi through candid employment contracts drawn up and signed at the proper time. Simply as a practical matter, the post-1940 reliance of the AAUP on the prophylactic power of this device would often prove to be misplaced. Though the limitations clause made no direct attempt to reduce the scope of religious tests (it spoke of religious "aims," not just of religious "credenda"), it was hoped that the "in writing" requirement would be helpful in this regard, that the very act of composition would compel college authorities to record the crux of required belief and eschew demands for adherence to nonessentials. Unhappily, as the litigation virus began to work its way into academic life, and employment contracts came to be written with the understanding that they might one day be construed in court, the precursive religious test became more likely to reflect the studied subtlety of the college lawyer than the artless musings of the religionist. Far from inspiring forthrightness and restraint, the “in writing" rule put a premium on ambiguity that left plenty of room for post hoc administrative construction. Literary craftsmanship descended to literary craftiness when faculty candidates at the appointment gate were asked to pledge "faithfulness to the spirit of a Christian college" or "adherence to the

administrative spokesmen and AAUP investigators it had not had in its earlier formulation. It should be borne in mind, however, that easily half of the complaints brought by faculty members in religious colleges alleged mistreatments that had nothing to do with religious tests and did not spark controversy over the meaning of the limitations clause. 
standards of the Church" (the details to be entered later). ${ }^{48}$ In the typical situation, very broad primary legislation was enacted at the threshold, and later, when the situation warranted, an expedient secondary legislation filled in the gaps. ${ }^{49}$

Had it been completely free to speak its mind, the AAUP would surely not have put everything it had to say about religious tests into an elliptical "limitations clause." On its own, in a more pliant format, it might well have taken fresh pains to insist that academic freedom, though in part the child of religious consciences, was historically the enemy and is logically the antithesis of religious tests. Drawing on twenty-five years of case experience, it might have concluded that prevenient religious tests were not clearly superior to sequent tests given without early warning, if only because their vagueness and overbreadth could just as well turn them into surprise attacks against faculty members. With room for exploration, it might have asked whether academic freedom is less offended when religious tests are administered selectively-to theologians but not to physicists, to coreligionists but not to gentiles, to clerics in the sponsoring church but not to ordinary communicants ${ }^{50} \longrightarrow$ or

48. Before 1940, the AAUP occasionally found itself embroiled with administrators who claimed that a by-law reference to the "Christian" character of the institution adequately warned would-be faculty members of the dogmas they were expected to profess. See H. D. Wolf \& Newman I. White, Report on Converse College, 20 AAUP Bull 434 (1934) (case of Peter Carmichael). After 1940, the AAUP could use the limitations clause-especially its demand for written prespecifications-to argue that so vague a description was no substitute for precise doctrinal demands. This approach put the AAUP in the strange position of advocating more rather than less prior restraint. Never quite satisfied that the early warning had been clear, specific or exhaustive enough, the AAUP would sometimes turn the limitation clause to the advantage of the complainant. In one case, it claimed that a college's designation of itself as "an instrument of witness for the Presbyterian Church" did not sufficiently warn the faculty member that acceptance of the divinity of Christ was required. Case file, King College-Marshall (1974) (AAUP files). In another case, it argued that a priest who is not told before appointment that he would forfeit his position if he resigned from the priesthood may not be dismissed for doing so later on without violating the limitations clause. William P. Berlinghoff \& Rodger Van Allen, Academic Freedom and Tenure: Seton Hall University (New Jersey), 71 Academe 28 (May-June 1985) (case of Leonard Volenski). Interestingly, when institutions did state their creedal restrictions with great specificity (these tended to be highly sectarian and insular institutions), the AAUP could not bring itself to approve. In one religious college case, a strong argument against the front-loading logic of the limitations clause emerged when an AAUP team confronted a close-toperfect example of a proprietary institution. See C. William Heywood, Academic Freedom and Tenure: Concordia Theological Seminary (Indiana), 75 Academe 57 (May-June 1989) (case of Alvin J. Schmidt).

49. Often enough, the "secondary legislation"- the precise offense for which the deviater from the general limitation pays a price-is stated very generally too. In some AAUP cases, especially those that emanate from small women's colleges run by religious orders, the charge of creating a "scandal" is said to justify a dismissal under the 1940 Statement. The charge of "scandal," one AAUP investigating committee wrote, is "not susceptible to common and specific definition. To the President of Saint Mary's College and to some others, it meant bad public manners. To others, it meant inaccurate or volatile or ambiguous discourse. To still others it meant bad publicity. It meant everything and it meant nothing." John P. McCall, Walter D. Mink \& Bernard F. Reilly, Academic Freedom and Tenure: St. Mary's College (Minnesola), 54 AAUP Bull 37, 42 (Spring 1968) (case of Richard Caldwell).

50. Nothing in the 1940 Statement suggests that the same limitations must apply to all members of the faculty of a religious college. The AAUP has never rebuked a Protestant institution for screening its theologians but not its Latinists for correct belief, or a Catholic institution for applying stricter restrictions to Catholic faculty members than to non-Catholic faculty members, or for discriminating against apostates-provided the restrictions are specified beforehand in the terms of appointment. This permitted selectivity of restraint undercuts one of the chief arguments for 
when the college finds greater culpability in heretical teaching than it does in heretical research, or in academic than in personal nonconformity. ${ }^{51}$ Without an imperative need for tact, the AAUP might have repeated what it had written in 1915-that it challenged, not the right of missionary institutions to exist, but their right to conceal their character by pretending to be true colleges or universities-and it might have used the epithet "proprietary" to counter their claim to general public support. Finally, free to think things through for itself, the AAUP, forswearing the desire to enlist for combat duty against every religious college in the country, might yet have concocted rules of engagement that would have allowed it to do battle within its means. But the genre to which the AAUP was committed did not encourage such reflections and elaborations. ${ }^{52}$

In 1970, a committee established by the AAUP and the AAC to clarify nebulous or puzzling passages in the 1940 Statement noted that " $[\mathrm{m}]$ ost church-related institutions no longer need or desire the departure from the principle of academic freedom implied in the 1940 Statement, and we do not

precursive tests, for if what a religious institution stands for may vary from one discipline to another, or one privately bargained contract to another, it can hardly stand for anything clear and unmistakable in the public eye. On the other hand, since the proviso itself applies across the board, the AAUP has been able to hold that all academics, including priests under the discipline of a hierarchic church, are entitled to its protection.

51. The limitation clause appears in the paragraph concerned with freedom of teaching, which would seem to argue that it refers only to communications in the classroom. In general, the AAUP has taken the position that it may apply to publications as well. See Frank R. Kennedy \& Donald C. Bryant, Academic Freedom and Tenure: Mercy College, 49 AAUP Bull 245 (1963) (case of Austin Shelton, $\mathrm{Jr}$.). Whether the limitation clause applies to "private" or "nonprofessional" faculty behavior is an open question. In a recent case, the AAUP determined that the wedding of a divorced member of a Catholic university faculty was too unrelated to the issue of professional fitness and too squarely within the zone of private conduct to be subject to institutional discipline under the 1940 Statement. Jose M. Sanchez \& Paul H. Walter, Academic Freedom and Tenure: The Catholic University of Puerto Rico, 73 Academe 34 (May-June 1987) (case of Jeannette Quilichini Paz). But this has not been a rigorously maintained position, probably because it puts the AAUP in the uncomfortable position of drawing the boundaries of religion, and also because this approach really bypasses the limitation clause, whose concern is not with professional fitness but with religious compatibility.

52. On its own, the AAUP might have arrived with the following position:

We hold these truths to be self-evident, that every doctrinal limitation imposed by an institution upon a faculty member as a condition of employment is incompatible with the principle of academic freedom, that this incompatibility remains whether the limitation is applied to applicants for, or to present holders of, academic appointments, is framed in vague or specific terms, or is promulgated with or without faculty consent, and that an institution that imposes such a limitation and that claims to safeguard academic freedom is engaging in a form of deception that should be exposed and reproved. Nevertheless, it is our view that the existence or even punitive application of limitations does not call for an AAUP vote of censure unless it is attended by other departures from good practices, such as a failure to acquaint the faculty member of those limitations before appointment or a denial of due process in the course of terminating the appointment.

Judging from a recent case, the discriminative use of the censure instrument as a way of avoiding close combat with every proselytic college while holding fast to the AAUP patrimony under pact conditions may be in the cards. See Bertram H. Davis, Richard G. Hider \& Schubert M. Ogden, Academic Freedom and Tenure: The Catholic L'niversity of America, 75 Academe 27 (September-October 1989) (case of Charles Curran); Report of Commitle .t 1989-1990, 76 Academe 32, 32-33 (SeptemberOctober 1990) (Committee A's recommendation to censure Catholic University). For a critical view of this approach, see Michael W. McConnell, Academic Freedom in Religious Colleges and L'niversilies, 53 L \& Contemp Probs 303 (1990). 
now endorse such a departure." 53 This comment signified that, after thirty years on the books, the limitations clause could still be authoritatively interpreted as endorsing a departure from academic freedom-an exegetical defeat the AAUP could not have desired but did contribute to. Further, the comment assumed that the "endorsement" had been so overtaken by changes in the attitudes of religious colleges that it had lost its constituency and hence had lost its point. ${ }^{54}$ As it turned out, that assumption was premature. The liberalizing trend in American Protestantism and the modernizing breezes that blew through the Roman Catholic Church from the Second Vatican Council were destined to be countered by the resurgence of Protestant fundamentalism and papal opposition to Johannine reforms. As a result, there remains to this day no dearth of administrators of religious colleges who take comfort in the 1940 Statement's presumed assurance that they can eat their academic freedom cake and have it too. ${ }^{55}$ Until this moment, the AAUP has continued to apply the limitations clause in part because it recites everything in the 1940 Statement as a mantra, but mostly because it can squeeze droplets of faculty protection from the view that, unless it is premeditated and preannounced, a religious test may not validly take effect.

\section{Agenda Gaps}

History is full of telltale omissions, of dogs that solve mysteries when they do not bark. In this connection, the revealing omissions have to do with topics included in the 1915 Declaration that did not gain entry into the 1925 or 1940 Statements, and topics emphasized in the later documents that had simply been ignored before. A few examples:

In 1915, the founders of the AAUP, filled with a blossoming sense of professional self-importance, sought to enhance the power and influence of faculty members in the governing of their institutions. Because of the great diversity of policy-making mechanisms in academe and the widely disparate

53. AAUP, 1970 Interpretive Comments, in 1984 AAUP Red Book at 5 (cited in note 1).

54. Stenographic Record of the Joint Meeting of the AAUP and AAC to Reconsider the 1940 Statement at 64-77 and passim (February 26-27, 1969) (AAUP files).

55. Taking advantage of the limitations clause is not the only way in which this result can be achieved. The comment of a New York Supreme Court judge in a case involving the challenged appointment of the philosopher Bertrand Russell to the City College of New York shows that it can also be achieved by definitions. "Academic freedom" he wrote, "does not mean academic license. It is the freedom to do good and not to teach evil." Kay $v$ Board of Higher Education of the City of New York. 173 Misc 943, 951, 18 NYS2d 821, 829 (Sup Ct 1940). This definition has had special resonance in Catholic higher education. As Catholic Duquesne University once put the same idea: "Academic freedom, like all things finite, has its limitations .... The truth confines the human intellect within limitations that connote true freedom-freedom from error ... ." After this definition there followed sixteen "don'ts," the violation of any of which would constitute grounds for terminating a tenured apointment. They included giving support to any idea that undermined the "stability" of family life and any idea that fostered "materialistic Communism." Policies and Regulations Concerning Appointments to the Faculties of Duquesne University (1940) (AAUP files). Many academics in Catholic institutions now take strong exception to a definition of academic freedom that equates it with compulsion to tell the "truth," but this means that the AAUP liberal definition of academic freedom has found protagonists in what had once been a wholly unpromising sphere, nol that it is certain to prevail there. 
opinions in their own ranks about whether these mechanisms should be retained, dismantled, or reformed, the founders said nothing in their academic freedom essay about faculty participation in the legislative processes of their universities. They did, however, dwell on faculty participation in the judicial processes of their universities, and on this matter they exhibited very strong guild complexes. They made a lasting contribution to this aspect of academic governance when they proposed that the faculty, as a body, should judge the validity of dismissal charges leveled against any of its members: this was a key application of the concept of peer review. They made a contribution that lasted through the 1925 Statement when they proposed that the reappointment and nonreappointment of junior faculty should always be effected with the advice and consent of a relevant body of senior faculty. And they made a contribution that would have an exceedingly short life span when they proposed that, on academic freedom issues, the faculty body convoked to weigh dismissal charges should be not only the court of first impression but the court of last appeal. In 1915, these guildsmen argued that "in matters of opinion, and of the utterance of opinion . . ., [lay] boards cannot intervene without destroying, to the extent of their intervention, the essential nature of a university ...." They made the same point with regard to professional ethics: "[i]t is . . . inadmissible that the power of determining when departures from the requirements of the scientific spirit and method have occurred, should be vested in bodies not composed of members of the academic profession." 56 On these subjects, the authors of the 1915 Declaration were Manichean; "lay" meant partisan, self-interested, and uninformed; "professional" meant nonpartisan, disinterested, and knowledgeable.

The 1925 Statement incorporated two inventions of prewar professional self-assertiveness: the call for peer review of charges against permanent faculty members, and the provision for faculty consultation in the employment or disemployment of junior faculty personnel. But aside from these carry-overs (plus an ambiguous reference to a faculty magistrate to screen charges based on public speech offenses, discussed in Part IIE), the spirited professionalism of 1915 was not retained. Not a trace remained in the 1925 Statement of the lay versus professional conceit that filled the pages of the Declaration. In the pact statement, all cases in which the professional fitness of a faculty member was brought into dispute, including those involving academic freedom, were to be decided finally by the lay governing board. With this tethering of professorial ambition to the realities of campus power, the faculty hearing ceased to be a symbolic re-experiencing of the medieval consortio magistromum and became more an advisory instrument of the institutional authorities.

In 1940, what might be called the deguilding of the idea of academic freedom and tenure went a good deal further. This Statement retained the

56. 1915 Declaration at 38, 34; Appendix $A$ at 404, 402 (cited in note 13). 
notion of an independent faculty hearing, strengthened by due process innovations and weakened by an "if possible" qualification. But the involvement of full and associate professors in the retention and nonretention of instructors and assistant professors dropped out of the program of these treaty-writers, along with the faculty watchdog in public speech cases that the 1925 Statement had contrived. Meanwhile, no attempt was made to revive the conclusionary faculty verdicts called for in 1915 or the pledge that the local faculty would police the conduct of its own. ${ }^{57}$ There were two reasons for this now very wide agenda gap. One was that the professional had come to speak more in the voice of the white-collar employee than in the voice of the medieval master. The other was that the bid for faculty autonomy had to yield to the facts of campus hierarchy, or presidents and professors would never have been able to agree.

An agenda gap, it should be noted, may be caused by an early as well as a late omission. The authors of the 1915 Declaration totally ignored the threat posed to academic freedom and tenure by the problem of financial exigency. This was hardly because all the academic institutions they knew were prosperous. Given the decades-long tendency of the institutional population to grow faster than the student population and the large number of private academic firms with weak endowments and in chronic need of more paying guests, the AAUPers of 1915 must have been aware that pinched institutional budgets were a common fact of academic life. Perhaps they thought it infra dignitate to dwell on so crass a thing as cash. This may seem hard to credit today, but they did eschew materialism in the fashion of their day when they thought it "undesirable" that persons "should be drawn into the profession by the magnitude of the economic rewards it offers," and when they used up all the letters of the alphabet save the last one before they would deign to establish a committee on professorial salaries. Probably their main reason for not mentioning institutional economic privations is that they just did not believe it had much to do with freedom and tenure deprivations. They may well have been too sheltered to understand that an administration, merely by crying poverty, could have all the pretext it needed for removing permanent faculty members without hearings, and for making ideological or personal enemies walk the plank.

Oddly, though professors were not disposed to guard against the deceptive uses of financial exigency, their presidential partners of some years later were. On this issue, pride of first authorship belonged not to the idealists of the AAUP but to the realists of the AAC:

Termination of permanent or long-term appointments because of financial exigencies should be sought only as a last resort, after every effort has been made to meet the need in other ways and to find for the teacher other employment in the institution. Situations which make drastic retrenchment of this sort necessary should preclude expansion of the staff at other points at the same time, except in extraordinary circumstances. ${ }^{58}$

57. 1940 Statement at 3-4; Appendix B at 407-09 (cited in note 1).

58. 1925 Statement at 329 (cited in note 45) (emphasis added). 
In other words, the termination of a long-term appointment for other than proven cause had not only to be justified but in fact necessitated by straitened circumstances. The action had to be patently last ditch, although this did not mean such dismissals were impossible; if the financial crisis could not be alleviated by other means, the axe could fall. In instructing financially strapped institutions to find alternative employment for their deposed faculty members, this provision further implied that a budget is not an iron givenness but is a reflection of human interests and desires within relatively broad or narrow resources constraints, and that even relatively tight budgets usually leave margins for choice. Many years later, the AAUP, in its own Recommended Institutional Regulations, would add a stiff definition of financial exigency, an order of execution more protective of tenured than of nontenured faculty members, and temporary recall rights for the victims of retrenchment, to the tactics devised in 1925 to head off disingenuous claims to penury. ${ }^{59}$ Still, it was remarkable that the constructive skepticism of the presidents should have gone that far that early. They asserted in effect that faculty members should not be treated by colleges and universities in financial distress the way workers in automobile factories were treated by companies with lagging sales. They used the word "drastic" to describe an institutional action that blighted academic careers and hopes: anyone who would have preferred a cooler adjective, such as "regrettable" or "unfortunate" would have been quarreling with a principled position, not disputing words.

The 1940 Statement was written during the last years of the Great Depression, and many of its key tenure provisions bore the mark of those prolonged hard times. On the issue of financial exigency, however, it was strangely unresponsive to a reality that, one might have supposed, should have brought that issue into high relief. ${ }^{60}$ Although they performed wholesale surgery on no other part of the 1925 Statement, the framers of the second pact elected to eliminate the entire paragraph designed to block the removal of tenured faculty members for trivial or specious pocketbook reasons. In its place they inserted a laconic sentence: "Termination of a continuous appointment because of financial exigency must be demonstrably

59. Recommended Institutional Regulations on Academic Freedom and Tenure $\$ \S 4(\mathrm{c})$-(d), in 1984 AAUP Red Book at 23-25 (cited in note 1) (adopted by AAUP in 1976) ("RIR").

60. Up to the point where it resumed negotiations with the AAC, the AAUP had received a handful of complaints over terminations said to be caused by financial pressures but had responded to them rather perfunctorily. Once a president, in reply to an AAUP opening inquiry, stated that he was compelled by the state of the institutional budget to terminate tenured appointments, and no other reason for the action suggested itself, the AAUP either washed its hands of the case or published a brief statement of fact. 1930 case folder, Hiram College-DuBois; 1931 case folder, Transylvania College-Maney et al; 1931 case folder, Morningside College-Overton; 1931 case folder, Texas Christian College-Glaze (all in AAUP files). When it did publish a report critical of the administration in a financial exigency case, the AAUP did not avail itself of the protective tools made available to it in the 1925 Statement. 1931 case folder, Texas Christian-Smith et al (AAUP files); Report, 19 AAUP Bull 472-76 (1933); Illinois Wesleyan-Bennett, 20 AAUP Bull 447-49 (1934). In general, the attitude of the association seemed to be: money problems are acts of God and it is pointless to question or revile them; if some nonmonetary causal factor gives us leave to criticize the administration, let us do so; if not, let us advise our complainants to accept their fate. 
bona fide." If not quite retreat to 1915's blankness, since the call for a demonstration of good faith was a sign of concern, the replacement sentence was much less mindful than the 1925 provision of the parlous relationship between security of academic tenure and claims of financial exigency. True, it did assert that such claims had to be bona fide or else the dismissal of tenured professors on those grounds would be invalid. But it did not define the degree of economic hardship needed to authenticate a claim of financial exigency, and without an in extremis standard any financial strain, any budgetary squeeze, could plausibly justify an executionary act. ${ }^{61}$ But financial strains and budgetary squeezes are the usual lot of dependent institutions that can generate only a part of their working revenues, of nonmarket institutions that cannot pass on all their costs to final purchasers, and of eleemosynary institutions that always try to do more than they can afford. Accordingly, the exigency provision in the 1940 Statement threatened to let a chronic condition extenuate departures from tenure rules, and thus convert what was intended as an exception into what could very well become the rule.

Moreover, shorn of the objective tests of "good faith," the 1940 provision could be said to require nothing more than a sincere economism, which is easy enough to assume and very difficult to belie. On the strength of this provision, it could be argued that a department induced by the tunneled numerology of cost accountants to lop off professors teaching classes with low enrollments, or a school instructed to save money by ousting expensive senior faculty to improve its balance sheet, were acting in an economic spirit and thus presumably in "good faith." 62 This road easily led to the philistine

61. In RIR 4c, a bona fide financial exigency is defined as an "imminent financial crisis which threatens the survival of the institution as a whole and which cannot be alleviated by less drastic means" than the termination of one or more tenured appointments. RIR (cited in note 59). Perhaps no deliverance from the AAUP has struck administrators as more wrong-minded and unrealistic. They ask, is there no room in the AAUP scheme of things for prudent planning, that is to say, for a rational response to anticipated, though not yet present, ills? Must the ship be almost at the point of capsizing before it may lighten its weight by trimming its tenured crew? Must things get markedly worse before steps may be taken to make them better? The general AAUP response has been that anything less than an in extremis standard would pose a profound threat to academic tenure and academic freedom. One administrator records the view that a "financial exigency begins, not when a school is bankrupt, but when it has significant difficulty in supplying additional positions to departments in the ascendency." Ralph S. Brown, Jr., Financial Exigency, 62 AAUP Bull 5 (1976). Were this definition to prevail, and tenured faculty could lose their jobs to finance expansion as well as to effect contraction, tenure would become a nullity for all seasons. A court rules that a financial exigency exists when there is an "urgent need ... to restore the financial ability of a college to provide from current income . . . the funds necessary to meet current expenses, including debt payment and sound reserves, without invading or depleting capital." Lumpert v Ciniversity of Dubuque, (\#39973, lowa state district court unreported, 1974). This was to say that the claims of tenure were to be subordinated to the claims of benefactors who wish to keep their bequests intact, to the claims of creditors who may be as varied as the local stationers and local fuel company, and to the squirreling instincts of trustees who may wish to turn surpluses into nest-eggs against the day when deficits might appear. It should strike no one as surprising that the AAUP looked askance at a definition that put the claims of tenure at the very end of a line that stretched around the block.

62. According to the AAUP gloss in RIR 4c, to be validly claimed, a financial exigency must threaten the survival of the institution "as a whole" and not just one or more of its subcomponents. In a multi-campus system, this would mean that the entire system would have to be on the verge of bankruptcy before any campus could be exempted on financial grounds from the rule that tenured faculty members may be dismissed only for adequate personal cause established in a due process 
assumption, widely shared in the more Westinghouse reaches of academe, that tenure rested provisionally on teacher productivity and student fads. ${ }^{63}$

What were they thinking of-those representatives of the AAUP and AAC who traded a strong statement on financial exigency for a weaker one? Their thinking is not fully disclosed by the skimpy conference record on this subject, but an article by President Henry M. Wriston of Brown University, a powerful figure on the AAC team and the author of the replacement sentence, increases our ability to read their minds. ${ }^{64}$ In 1940 as in 1925, the professors left it to the presidents to decide what, if anything, should be said about financial exigency. Their persistently phlegmatic attitude may be explained in part by the fact that the Great Depression took a much lighter toll on the senior faculty, to whom the exigency exception alone applied, than on the junior faculty, who were always vulnerable to ejection for unstated reasons. This fact convinced Wriston that tenured professors had less to fear from a shrinking fisc than from spurious financial arguments used by administrators who were trying to run for cover. It had been his experience, he wrote, that presidents would rather blame the discharge of a faculty member on the limitations of the budget than on the limitations of the faculty member, the former being almost always present and the latter being almost always painful. Wriston regarded this kind of disingenuousness, even if motivated by kindness, as inimical to sound personnel practices, and it was to stiffen the backbone of his colleagues that he plumped for a bona fide clause. But this explanation does not explain everything. Wriston was well aware that plots against tenure

hearing. Getting boards and administrators to agree, especialy in the public sector, has proved to be a difficult and even perhaps a futile task for the AAUP. But the alternative-to accede to attacks on tenure by the simple expedient of starving certain institutions in a system through managerial decree-is even more unappealing. RIR (cited in note 59). For AAUP cases that raise the whole-part issue, see City University of New York: Mass Dismissals Under Financial Exigency, 63 AAUP Bull 60 (1977); University of Idaho, 68 Academe Ia (1982); The State University of New York, 63 AAUP Bull 237 (1977). The courts have not been friendly to the AAUP argument that financial exigency in a subcomponent is but another word for inefficiency, that is, the less than optimal use of personnel-and that this should not be a valid basis for rescinding tenure. Scheuer, 199 Neb 2d at 624, 260 NW2d at 601 . David Fellman, The Association's Evolving Policy on Financial Exigency, 70 Academe 14 (1984).

63. RIR 4c allows for irregular dismissals when a program or department of instruction is discontinued for primarily educational reasons. RIR (cited in note 59). This second exception was not covered or even contemplated by the financial exigency clause of the 1940 Statement. Committee $A$ reasoned that an institution should not be barred by the rules of tenure from dropping an educationally unworthy program-an engineering school that had become technologically outmoded, a department of linguistics that had lost its stellar cast and could not replace it. an undergraduate program in journalism that had become a patent waste of the students' time. If tenure positions are forfeited as a result, the AAUP was prepared to live with it, although the association enjoined the institution to make "every effort" to find a "suitable alternative position" for every tenured professor thus displaced. This was a large concession to quality on the part of the AAUP, and it had the capacity to cause mischief in several ways. For one thing, the "program" could be so small that its excision was tantamount to a dismissal of one individual without due process safeguards. Browzin, $527 \mathrm{~F} 2 \mathrm{~d}$ at 849 . For another thing, institutions have interpreted this exemption as permitting them to reduce a program in the interest of economy without a showing of financial exigency, an interpretation that subverts the educational aim of the discontinuance clause and negates the RIR effort to define financial exigency.

64. Henry M. Wriston, Academic Freedom and Tenure, 25 AAC Bull 110 (1939). This article is an invaluable source of information about what transpired in the conferences up to that point, seen from a president's perspective. 
could be hatched by the business mentality in academe. In the same article, he argued that "the displacement of a [permanent] teacher should not be done merely as an 'economy' move, but [only] because of a genuine emergency involving serious and general retrenchment." 65 This comment leaves two questions searching for an answer: Why, if Wriston was willing to define financial exigency so rigorously in an article, did he not do so in the 1940 Statement? And why, if a president could see the point of 1925's protective clauses, did the professors, who had more to gain from them, not lift a finger to retain them in the next negotiating round?

\section{What If?}

Every discussion so far under "genre effects" and "agenda gaps" points to effects attributable to the pact; there has been little explicit assessment of the contributions of the pact-partners. But the company the AAUP chose to keep doubtless did help shape the document it agreed to. The influence of the presidential participants can be seen in many parts of the 1940 Statement, but perhaps nowhere is it more luminously displayed than in the cautionary language in the academic freedom section. It is here that one especially feels bound to ask "what if?"-what if the AAU and not the AAC had joined hands with the AAUP in 1925 and 1940 ?

Under "freedom of investigation," the working draft of the AAC in 1925 read as follows: "a university or a college may not place any restraint upon the teacher's freedom in investigation unless restrictions upon the amount of time devoted to it becomes necessary in order to prevent undue interference with teaching duties, which are the primary function of the college instructor." 66 Probably because Lovejoy's scissors went to work, the last nine words were snipped from the final draft. But they held the key to the AAC presidents' thoughts. Ever since the late nineteenth century, when scholarly and scientific inquiry was first incorporated into the roles academics were expected to perform, there had developed a growing library of complaint about the tendency, in this wedding, of the entrepreneurial activity of research to foster faculty neglect of the institutional obligation to teach. The notion that scholarship was the vile seducer and teaching the slighted spouse became canonical among traditional educators in the undergraduate institutions before World War I and among progressive educators afterwards, and it probably had a resilient appeal to presidents of AAC teaching-centered colleges, who were fond of proclaiming that marital fidelity in professional matters was their stock in trade. ${ }^{67}$ The 1915 authors had made no such charge against research; if anything, they personally believed that the sin of infidelity went the other way, that grading too many freshman papers and

65. Id (emphasis added).

66. First Draft, 1925 Statement (Maguire files \#10, AAUP files) (emphasis added).

67. The strong survival of an antiresearch ethos has been documented by Laurence R. Veysey, The Emergency of the American University (doctoral dissertation, University of California at Berkeley, 1961), especially in chapter four. 
doing too many household chores drew faculty members away from their truest love, sustained inquiry. And it is probable that their presidents, toward whom the published and publicized research of faculty members wafted the sweet smell of success, did not share the view of their collegiate brethren that writing books and conducting experiments were comparable to acts of adultery.

By 1940, the AAC presidents had become less touchy on this subject. Using a Maguire redraft that sought "only to improve the language" and again did somewhat more, they agreed to a milder formulation of their old position: "the teacher is entitled to full freedom of research and in the publication of the results, subject to the adequate performance of his other duties." This setting of faculty priorities seemed sufficient to safeguard the institution's interest until Tyler, drawing on his MIT experience, suggested an additional proviso: "but research for pecuniary return should be based upon an understanding with the authorities of the institution." Apparently, the idea that faculty research could be a means of institutional as well as individual self-advancement had not fully dawned on the world of the colleges, or else the presidents would not have needed a professor to remind them that the vamp that made them so uneasy could be required to help pay their bills. ${ }^{68}$

Was there not more to be said about freedom of inquiry at that time? In 1940, academic research was on the threshold of wartime and postwar transformations. Some problematic aspects of that looming future could even then be glimpsed. If academic "big science" had not yet reached the Brookhaven scale of costs, it had sufficiently soared over the Edisonian scale of 1915 to offer portents of academic freedom and tenure threats soon to come. Already academic statesmen were wondering in print how freedom of inquiry could be protected in the face of large-scale federal support, classified military research, security clearances for academic personnel, and the huggermuggeries of the national police. The handwriting on the wall also pointed to serious tenure problems. Although the number of full-time researchers without teaching responsibilities would not explode until after the war, it was already large enough to raise the question of whether full-time researchers on soft money should be eligible for tenure citizenship and, if not, how professionalism could be squared with the predestinarianism doctrine that nothing certain academics do can ever earn them salvation. The leaders of the AAUP, who, as before, were associated with major research universities and were still distinguished figures if not lions in their disciplines, might well have examined these issues with presidents from the AAU, which was a less exclusive organization than before, but still consisted of the leading research centers. Even if they could not have found common ground on emergent issues, they might well have made headway against long familiar issues

68. Maguire redraftings of the 1940 Statement, 1940 Statement folder (AAUP files). These revisions of the 1925 Statement would be modified at many points when they were taken up by the negotiators, but so much of their structure and verbiage survived that they are indispensable to a reconstruction of the evolution of the final text. 
touching on the ethics of academic research, such as the propriety of concealing knowledge to protect a prize or patent, or of accepting gifts for research from special interests with ideological ambitions, or of conducting experiments under academic auspices that could be harmful to the environment or human subjects. To some degree at least, the thinness and brevity of the commentary attending "freedom of investigation" can be laid to the inexperience and lack of interest of the AAUP's actual interlocutors.

One can also find indications under the heading of "freedom to teach" that matters might have taken a different turn if the AAU and not the AAC had joined with the AAUP. In 1915, the Seligman contingent devoted a thoughtful paragraph to the problem of the unseasoned student in the college classroom who may be vulnerable to culture shocks. They did not offer a clear directive to the academic teacher on this matter. On the one hand, they warned the teacher to be especially on guard against "taking unfair advantage of the student's immaturity by indoctrinating him with the teacher's own opinions upon the matters in question ...." On the other hand, they held it to be the teacher's duty "to give to any students old enough to be in college a genuine intellectual awakening," and they supported this position with the aphorism that "it is better for students to think about heresies than not to think at all ...." In the end, they left the issue up to the "pedagogical wisdom" of the individual instructor convinced that, on this delicate ice, heavy-footed codifiers should fear to tread. ${ }^{69}$

The AAC presidents felt no such inhibitions. In the draft they brought to the 1925 Conference, they treated the presence of immature students not as an argument for sensitive teaching but as an exception to instructional freedom. A university or college may not impose any limitation "except in so far as the necessity of adapting instruction to the needs of immature students .. . limit the scope and character of instruction." They felt so strongly about the danger of pedagogical domination that they devoted a separate paragraph to it: "No teacher may claim as his right the privilege of discussing in his classroom controversial topics outside of his own field of study. The teacher is morally bound not to take advantage of his position by introducing into the classroom provocative discussions of irrelevant subjects not within the field of his study."70 The AAUP, perhaps more than half-agreeing, did not demur.

"What if?"s can no more be proved than can any other fling of the imagination, but it is hard to believe that the presidents of Chicago, Johns Hopkins, and Columbia, accustomed to mature graduate students and urban if not always urbane undergraduates, would have pictured their own classrooms as stages on which faculty Svengalis sought to seduce the minds of student Trilbys. And it is also hard to believe that they would have remained quite as eager as their collegiate counterparts to tell academics how to teach even after they stopped drumming up this melodramatic classroom plot. In 1940 , again working with one of Maguire's supposedly minimal redrafts, the

69. 1915 Declaration at 35, 36; Appendix $A$ at $402-03$ (cited in note 13).

70. 1925 Statement at 329,330 (cited in note 45). 
AAC presidents agreed to drop all reference to the problem of student immaturity-apparently their own colleges were running out of students who could be scared out of their wits by a new idea. They thus abandoned the view that the innocence quotient of the audience should determine the amount of freedom a teacher should enjoy. But they did not relinquish all their apprehensions about the don's capacity to mesmerize and mislead. Without much argument from the AAUP, they continued to insist that academic teachers should stick to their subjects. For a time, the word "controversial" dropped away (as did "provocative"), but then the former was restored by the committee on style. The final version read: "The teacher is entitled to freedom in the classroom in discussing his subject, but he should be careful not to introduce into his teaching controversial matter which has no relation to his subject." 71

A total break with the past would have been more clarifying than this softer recapitulation of it. Not making clear what at root was objectionablethe controversialism or the digressiveness-the authors left it up to their readers to decide whether a wandering teacher would be in bounds if he provoked no classroom argument, and whether an arrant polemicist would be safe if he but stuck to his original syllabus. In 1970, the AAUP-AAC committee on interpretation stated that the intent of this passage had not been to discourage controversy but to "underscore the need for the teacher to avoid persistently introducing material which has no relation to his subject."72 According to this interpretation, the controversialist, the intellectual provocateur, and the Devil's advocate would all be safe, and only the irrepressible meanderer, no more beloved by presidents in the AAU than by those in the AAC, would run afoul of this admonition. It had taken many years and some fancy exegetical footwork to efface the stamp of the small college from this part of the 1940 Statement.

It may also be argued that a different cast of presidential characters would probably have written different cautionary lines for the passages on extramural freedom. The legislative history of these passages throws unique light on the important question of how all of these stated admonitions were to be enforced, and for this reason it will be given a somewhat closer look.

\section{E. Confrontation}

In marked contrast with the swift and harmonious exchange of views that cemented the 1925 Statement, the deliberations leading to the 1940 Statement were prolonged, volatile, and acrimonious. Not counting a series of informal meetings called by the AAC to protest the AAUP's handling of freedom and tenure cases, the two associations met officially four times between 1937 and 1940 to hammer out a revised freedom and tenure statement. Again and again the enterprise came to the verge of foundering:

71. 1940 Statement at 3; Appendix B at 407 (cited in note 1).

72. 1940 Statement at 5 (cited in note 1 ). 
Henry Wriston reported after the third encounter that "[t]here has never been a meeting when we did not think we might have to adjourn and throw up the task." 73 In October 1938, the conferees did reach an agreement that embraced the substance of the AAUP's positions on several issues. The AAUP council promptly approved it, but the AAC board of directors turned it down, objecting to concessions it interpreted as capitulations. It would take two more years before a meeting of presidents and professors would produce a meeting of minds and an outcome that both organizations would accept.

Why, after the smooth delivery of the first agreement, did the second one have such a painful birth? Part of the answer lies in the difficult personalities of the second group of accoucheurs. After a lapse of a half-dozen years, the AAC freedom and tenure committee was revived in 1934 with an entirely new cast of characters. The dominant figures on the new committee, now called a commission, would for some years be the presidents of relatively small colleges who picked bones with the AAUP using blunt utensils. The commission chairman, President J. L. McConaughy of Wesleyan University, had a grudge against the professors' association for what he regarded as its persistent maligning of the administrations of small colleges, and he was determined to do everything he could to make it stop. ${ }^{74}$ After proposing a joint national tribunal to hear and judge faculty grievances in place of the unreliable Committee A (a prevision of binding arbitration which most of his fellow presidents had no use for), he tried to get the AAUP to agree that it would not undertake to investigate a case, publish a case report, or censure an administration without first securing AAC (which was to say, his own) consent. ${ }^{75}$ Presuming that the AAUP had given him that veto power, he proceeded to pepper it with peremptory demands that this or that impending case be dropped because he had ascertained that it was wholly without merit, and that this or that administration be removed from censure because he had heard from its president's own lips that it had not erred. When the AAUP

73. Wriston, 25 AAC Bull at 111 (cited in note 64).

74. The strained relations between the AAUP leaders and the new AAC Commission leaders are detailed in correspondence that can be found in Committee A case folders, arranged alphabetically by rame of institution, for the period 1933-1938; the Maguire files, which were donated by Maguire to this author and were then deposited in the AAUP files; and the 1940 Statement folder. This correspondence, too voluminous to be cited extensively, provides the background for these personality analyses.

75. The first face-to-face meeting in November 1935 between Maguire and Mitchell, representing the AAUP, and McConaughy, representing the AAC, was explosive. The latter was reportedly livid in his complaint that college presidents had not been fairly treated by Committee A and that the AAUP was more sympathetic to universities than to colleges. Only the mollifying presence of President Wriston of Brown and Chancellor S. A. Capen of Buffalo kept it from ending in a rift that would have doomed any further negotiations. Maguire memo on the New York pretiminary meeting in November 1935, 1940 Statement folder (AAUP files). "I felt that the representatives of the AAUP were in an incomfortable position because they were guests, were much outnumbered, were encountering men who have the authoritarian habit, and were subjected to a concerted attack which had been prepared in advance." Letter, John M. Maguire to Walter Wheeler Cook and others (December 10, 1936) (Maguire files \# 10, AAUP files). 
balked, McConaughy threatened to sever diplomatic relations with it, which would have meant putting an end to renegotiating talks. ${ }^{76}$

For years Secretary Tyler had thought that a well-intentioned group of presidents might play a useful mediatory role in the early stages of a freedom or tenure case, and a number of AAUP leaders had toyed with the idea of joint investigations and of case reports over double signatures. But McConaughy, whom even his own colleagues described as tactless and overbearing, ${ }^{77}$ managed to get everybody's backs up and deal the idea of cooperative investigation a mortal blow. The Virginia astronomer, S. A. Mitchell, who as President of the AAUP had usually been accommodating toward administrators, told this thunderer of ultimatums that his organization would not accept the AAC's dictation. Walter Wheeler Cook, who took Tyler's place as part-time secretary in 1934, found in McConaughy's effort to hold the pact negotiations hostage to the success of his importunings proof that the replacement of the all-faculty Committee A by a two-headed constabulary or judiciary would be a suicidal form of unilateral disarmament. ${ }^{78}$

If McConaughy roiled the negotiations with his imperious temper and leaden ear, President W. C. Dennis of Earlham College, the only AAC delegate to attend all the drafting sessions, burdened the conference with a lawyer's analytic mind put to the service of obsessive negativism. Dennis was troubled by so many issues, both those under review and those long settled, that one can only conclude that he was characterologically inclined to look for trouble. Starting out with the apprehension that church-related colleges, if they adhered to the principle of academic freedom, might have to sanction the "use of profanity" (the bemused Carlson replied that a little "cussing" would not do students abiding harm), Dennis wound up with a more general concern about the viability of faculty hearings in small colleges and the soundness of exempting the extramural utterances of faculty members from institutional constraint. ${ }^{79}$ It was he who persuaded the AAC Board to reject the agreement reached in 1938, and it was to keep him from submitting yet another minority report that the other participants at the final meeting expended all the politique energy they could command.

It is a commentary on the schizoid character of the AAC that even while it was attracting more presidents from large urban universities than ever before it allowed this sensitive commission to come under the sway of presidents

76. Letter, J. L. McConaughy to S. A. Mitchell (December 17, 1935); letter, J. L. McConaughy to H. W. Tyler (February 1, 1936) (threatens to break off negotiations unless DePauw College was removed from the censure list) (Maguire files \#10, AAUP files). 1933 case folder, De Pauw CollegeHuffered; 1935 case folder, Culver Stockton College-Graham (all in AAUP files).

77. Letter, John M. Maguire to Anton J. Carlson, reporting Wriston's evaluation of McConaughy (April 17, 1937) (Maguire files \# 10, AAUP files).

78. Letter, S. A. Mitchell to J. L. McConaughy (February 12, 1936); letter, H. W. Tyler to J. L. McConaughy (February 10, 1936); letter, Walter Wheeler Cook to H. W. Tyler (February 10, 1936) (Maguire files \#10, AAUP files). 1936 case folder, Coe College-Ogburn (AAUP files).

79. Remarks of W. C. Dennis (Notre Dame educational conference under the auspices of the AAC, October 1936), 1940 Statement folder (AAUP files); Carlson report on that conference to Himstead and others (October 22, 1936) (Maguire files \#10, AAUP files). 
who, if not quite the 1916 cohort redivivus, were too set in their provincial ways and too suspicious of the AAUP ever to be confused with the fraternizers of 1925. This is not to say, however, that the AAC had a monopoly on rigidity, querulousness, and confined perspectives. In 1936, just as the redrafting process got underway, the AAUP chose Ralph $E$. Himstead to be its first full-time general secretary. That appointment marked the beginning of the modern history of the AAUP-a history that includes the routinization of initial charisma, a significant growth in membership and influence, a neardebacle during the McCarthy period, and a renaissance under new leadership after that. More immediately, the arrival of Himstead had the effect of worsening the already bad personal chemistry of the meeting room. A thinskinned law professor from Syracuse University, where he had come to detest its authoritarian president, Himstead had less tolerance for the vanities and insults of that breed than did most of his better-connected, less-embattled colleagues. ${ }^{80}$ Inevitably, the correspondence between the new general secretary and the Wesleyan president grew so heated that calmer heads among AAUP leaders, fearful that this fire might consume the budding negotiations, proposed to scan the letters sent from Washington to Middletown and, if necessary, hose them down. ${ }^{81}$ Himstead's negotiating skills were noticeably poor when McConaughy was in the chair or even in the room. It was no coincidence that he began to reveal a talent for give-and-take only after McConaughy left the AAC Commission and Wriston took the gavel and, with the help of S. P. Capen, the worldly chancellor of the University of Buffalo, set the tone.

On most matters dealt with by the 1940 Statement, the two camps were not at each other's throats. It is simply not the case that the professors fought for freedom while the presidents fought for restrictions, or that one side believed in tenure while the other side did not. Many differences that cropped up in discussion were over nuances of phrasing and were resolved without personal animosity. But two issues could not be readily resolved, and it was these issues that invited testy egos to do their worst. One issue concerned the AAUP's proposal that all probationary periods be of a standard

80. Of all the AAUP leaders, Himstead was the least enthusiastic about renegotiating the original pact with the ACC. "Personally I am sorry that it was suggested at our March conference that we consider revising our tenure rules ... I doubt whether at this time we can come to any agreement with McConaughy's committee ...." Letter, Ralph E. Himstead to Anton J. Carlson and others (October 23, 1936) (Maguire files \#10, AAUP files). Even after the negotiations began, after strong urging from Carlson of the AAUP and Wriston of the AAC, he remained a persistent advocate of caution and delay. The reason was not just his profound antipathy for McConaughy and his sort; he also feared that the local chapters, then in the throes of a periodic attempt by the rank and file to wrest decisional authority from the Washington Office, would interpret the negotiations as consorting with and giving comfort to the enemy. He was resolved to tell the members as little as possible about the progress of meetings; indeed, he did not reveal that a revision of the 1925 Statement was their purpose until a new agreement was actually reached in 1938. Ralph E. Himstead, Report of the General Secretary, 23 AAUP Bull 570 (1937). Letter, Ralph E. Himstead to Walter Wheeler Cook (December 2, 1937), Cook folder, 1937-1943 (AAUP files).

81. Letters, John M. Maguire to Anton J. Carlson (April 17. 1937), and Anton J. Carlson to John M. Maguire (April 20, 1937) (Maguire files \#10, AAUP files). 
as well as a fixed duration; more than a technical follow-up to 1915 or 1925 , this was a transformative idea that went far beyond contemporary personnel practice. The second issue involved the AAC's desire to subject the public utterances of academics to institutional discipline; this too contemplated a leaping change, but less into the untrod future than into a partly transcended past. Both issues, it should be noted, created divisions within the AAUP and the AAC as well as between them. This was a saving grace, for strictly twosided confrontations would have been a recipe for polarization and paralysis.

The authors of the 1915 Declaration gave a seemingly contradictory answer to the question of how freely faculty members might express themselves in public forums on matters not related to teaching or research. On the one hand, still in touch with the religious roots of their calling and eager to protect the good name of their profession, they insisted that academics reach a limiting line of professional propriety long before they reach the boundary between legally protected speech and libelous, seditious, or obscene utterances. They thought it "obvious" that faculty members in their role as citizens should abide, not by the maximalist doctrine that anything goes if it is within the law, but by the realization that they had a "peculiar obligation to avoid hasty or unverified or exaggerated statements, and to refrain from intemperate or sensational means of expression." On the other hand, opposed to any suggestion that academic teachers, like many schoolteachers, had to shed their constitutional liberties when they passed through the campus gate, they maintained in the very same paragraph that "it is neither possible nor desirable to deprive a college professor of the political rights vouchsafed to every citizen." (They left open for discussion the question of whether academic social scientists would risk their reputation for disinterestedness if they ran for public office or managed a political campaign. ${ }^{82}$ ) They thus faced the problem of reconciling two opposed ambitions-to hold the academic professional to high standards of public conduct and to secure for the academic professional the ordinary right to free speech.

It is instructive to note how the authors of the 1915 Report chose not to solve this problem. They did not attempt to distinguish between the form of expression (which would be subject to demands of public etiquette) and the content of expression (which for freedom's sake would be best left alone). Indeed, they explicitly rejected this stock approach to the reconciliation of liberty with respectability: "It is . . . in no sense the contention of this committee ... that individual teachers should be exempt from all restraints as to the matter or the manner of their utterances . . .." Nor did they contend that academic freedom, even under constraints, bestows more freedom on faculty members than other citizens customarily receive, since it displaces no legal civil liberty, yet offers protections from economic penalties that may elsewhere repay dissent. With a keen eye for the argument that would be

82. 1915 Declaration at 37-38; Appendix A at 404 (cited in note 13). 
most appealing to the public, they preferred to stress the sacrifices professors volunteer for and not the preponderating privileges they retain.

The 1915 solution was to make all strictures against professionally unbecoming public speech matters for professional, not lay, enforcement. To the greatest degree possible, they urged that the etiquette of academic public speech be "self-imposed." Coming from homogeneous social and cultural backgrounds, these AAUPers could believe that most faculty members would conduct themselves properly in public even when left entirely on their own. Where self-enforcement proved insufficient, they thought a canon of decent discourse could be "enforced by the public opinion of the profession"-that is, by fear of collegial disapproval.

Had they said no more, they would have made freedom of extramural utterance practically coextensive with legally defined freedom of speech, since professional admonitions would have been merely precatory. But the founders of the AAUP, like the founders of the nation, were too pessimistic about the moral perfectibility of human beings to trust the task of human betterment wholly to personal upbringing and communal pressure. They conceded that "there may, undoubtedly, arise occasional cases in which the aberrations of individuals may [have] to be checked by definite disciplinary action." 83 By saying this, they admitted that what faculty members say and write in off-campus settings and during their off-duty hours may in principle be used against them in institutional trials looking to their dismissal. But if the institution could take cognizance of a faculty member's public speech in a disciplinary hearing, and if the faculty member is not protected by a rule of evidentiary exclusion, would the faculty member not be "deprived of political rights vouchsafed to other citizens?" The authors of the 1915 Declaration answered that irrepressible question by rehearsing the key articles of their guildist faith. Such a deprivation would occur, they wrote in effect, if lay governing boards were to judge a faculty member guilty of unprofessionalism in public discourse. But it would not occur if such judgments were rendered by the profession itself, which was to say, by the local faculty. Did history not teach that when colleagues are their brothers' keepers, personal vendettas, party dogmas, and petty tyrannies are very likely to result? The 1915 authors made no mention of the dangers of collective oversight. They sought only to convince the governing boards that anarchy would not ensue if they steered clear of extramural utterances and let the faculty police that zone. They pledged

that the profession will earnestly guard those liberties without which it cannot rightly render its distinctive and indispensable service to society, [while] it will with equal earnestness seek to maintain such standards of professional character, and of scientific integrity and competency, as shall make it a fit instrument for that service. ${ }^{84}$

This was one place in the 1915 Declaration where epiphany supplanted explanation.

83. 1915 Declaration at 38; Appendix A at 404 (cited in note 13).

84. 1915 Declaration at 39; Appendix $A$ at 405 (cited in note 13). 
The 1925 Statement compressed this convoluted issue into two brief sentences:

(a) A university or college should recognize that the teacher in speaking and writing outside of the institution upon subjects beyond the scope of his own field of study is entitled to precisely the same freedom and is subject to the same responsibility as attach to all other citizens.

(b) If the extra-mural utterances of a teacher should be such as to raise grave doubts concerning his fitness for his position, the question should in all cases be submitted to an appropriate committee of the faculty of which he is a member. ${ }^{85}$

In all probability, these formulations, which came from the AAC presidents, were quite pleasing to the Lovejoy team. The AAUP had been agreeably surprised by the strong support given by the presidents to the principle embodied in (a). What was said in (b) contained one key idea in the 1915 Declaration-that extramural speech enjoyed no absolute immunity from the prosecutorial reach of the institution-and was half supportive of another-it agreed that the faculty should be the first to pass judgment in public speech cases (though it said nothing about whether or not that judgment would be the last). Conspicuously missing was sentence (c)-a list of speech offenses that faculty members were told they must assiduously avoid. Instead of reiterating the prohibitions of 1915, the 1925 Statement simply said that whenever anything said or written in the public sphere raises "great doubts" about the speaker's or writer's "fitness for his position" it may spark a disciplinary action. As a member of the committee on style, Lovejoy had an opportunity to refurbish the text in the course of polishing it, but he chose not to add the monitory furniture of 1915. His reason seems obvious enough. Uninhibited about using terms like "sensational," "hasty," and "unverified" as finger-waggings at members of the profession who would be the sole judges of their sweep, the leaders of the association shied away from doing so in a pact that left the faculty with no exclusive jurisdictions or conclusive verdicts, and that would have allowed emotion-laden terms of uncertain meaning to be used as lethal tools by governing boards and administrations. And at that time the AAC presidents did not insist on enumerating the punishable improprieties of faculty public speech.

But in a later day they would. During the next decade, the vituperations and petty conspiracies of cellular left-wing politics, along with attempts by the American Federation of Teachers ("AFT") on certain campuses to organize and mobilize the resentments of junior faculty, gave some administrators a bad case of jitters. These were mostly big-city, east and west coast aggravations; elsewhere, many administrators found that faculty public speech, strident in the best of times, had been made more so by the provocations of the Depression. By the mid-1930s a number of AAC presidents were convinced that the failure of the 1925 Statement to specify certain speech acts as unconscionable was a flaw in urgent need of correction. The Commission on Academic Freedom and Tenure owed its revival to this

85. 1925 Statement at 330 (cited in note 45 ). 
particular dissatisfaction with the old agreement, and its agenda for the first formal meeting with the AAUP, held on its initiative, had mainly this revisionary end in view.

Most AAUP leaders held a different view-they thought it had become more necessary than ever to protect the citizen in the academic. The passing years had only reaffirmed what the founders had discovered: that academic freedom was most vulnerable to attack not in the laboratory or the lecture hall but in the civic forum. The association had had to deal with relatively few cases of alleged infringements on freedom of research, in part because researchers communicating with fellow researchers were seldom overheard or, if overheard, were not easily understood; in part because scholars and scientists whose discoveries disturbed the peace were likely to be rewarded for doing so, and winners of Nobel Prizes were not apt to complain to the AAUP. The association had dealt with more cases involving attacks on freedom of teaching, especially in proselytical colleges, but these, too, were relatively infrequent, probably because happenings in the classroom were almost as shielded from outside observation as were occurrences in a confessional. But extramural utterances-in earshot of unfriendly listeners, seldom in need of decoding, generally unsupported by the authority of the chair or the panache of a learned discipline-did not have the same protective covers yet could stir up the most potent foes. Most of the cases handled by Committee $A$ up to that time had been academic tenure cases, pure if not always quite so simple; of those that were academic freedom cases, the vast majority were extramural freedom cases; in that group, the typical cause of an academic freedom violation was the dismissal either of a faculty member accused of riling an important public and thus bringing the institution into disrepute or else of a faculty member held to be insubordinate by administrators who equated loyalty to Alma Mater with subservience to themselves. Any proposal by the AAC presidents to strengthen the hands of administrators in an area where academics were so exposed was bound to make the AAUP leadership uneasy. "I fear our friends in the Association of American Colleges have in mind to find some way to cut down freedom of expression, especially off the campus," Cook wrote to Carlson. "We must watch our step and not allow anything of that kind to happen." 86

The AAUP had read the intentions of their old partners correctly. The AAC delegates came to the first meeting with the AAUP in October 1937 with a stack of fresh proposals. They would repeat sentence (a) of the 1925 Statement, which applied only to academics speaking and writing outside the classroom and their own field of study. But they proposed to lay down new restrictions for teachers doing other things:

The teacher speaking and writing on his own subject outside the classroom should do so soberly and seriously, not for notoriety of self-advertisement, under a deep sense of responsibility for the good name of the institution and the dignity of his profession.

86. Letter, Walter Wheeler Cook to Anton J. Carlson (October 28, 1936), 1940 Statement folder (AAUP files). 
Or, as an alternative:

In statements on his specialty outside the classroom the teacher's loyalty to the institution may necessarily curb the "freedom of speech" enjoyed by the citizen who is not an employed teacher.

Several closings to these pronouncements were suggested by the presidents:

$[T]$ he teacher in speaking and writing outside of the institution upon subjects beyond the scope of his own field of study is entitled to ... the freedom [of] other citizens, [but he] should speak or write with the restraint and good taste of a scholar, recognizing that the public will judge the institution by his utterances [and should understand that extramural freedom] is not an aspect of academic freedom.

Or else:

Even when faculty members make it clear that they are expressing their personal opinions the institution to which they belong will be held responsible for what they say.

In this flurry of new language, the 1925 provision for a faculty screening mechanism in public speech cases was brushed aside. Without actually saying so, the presidents left no doubt that enforcement of these stern commands should be an administrative responsibility. ${ }^{87}$

The AAC presidents had not reasoned very cogently on this issue: why should faculty members be under tighter constraints when they speak in public about something they have studied than when they deliver opinions on matters beyond their ken? But clearly, this issue inflamed them more than any other; on no other did they go to the trouble of formulating alternatives to the standing text, let alone do so with incendiary language. The AAUP representatives at this initial session (Himstead, Carlson, Cook, Tyler, Maguire, and Laprade, a Duke historian who had just become chairman of Committee A) sensed at once that the presidents had launched a groping assault on one of their bastion principles. They were not about to agree that extramural freedom should be separated from academic freedom, especially when the purpose of that divorce was to give institutional loyalty a higher value than freedom of expression. But they chose to avoid a head-on collision over words that had been offered provisionally, and more as fulminations than as polished prose. They proposed that their own Maguire, whose editorial skills had already been put to work on other parts of the academic freedom section, should try his hand at this troubling part, and all agreed that he should reconcile conflicting viewpoints in a sense-of-the-meeting note that would be entered retrospectively into the minutes. That tall order would have fateful consequences.

Then in his tenth year of service to the AAUP, Maguire had been hired by Tyler as a part-time legal consultant to assist the association in a threatened libel suit that did not materialize, and had stayed on as adviser to Committee A and as the secretary's alter ego. After Tyler's departure from the secretary's office, Maguire had been called upon less often to lend a helping hand. With the arrival of Himstead, who had a notorious incapacity to delegate authority

87. Typescript, AAC on "Academic Freedom," 1940 Statement folder (AAUP files). 
and who thought that two lawyers on the premises were twice the desirable number, Maguire had moved to the outskirts of AAUP leadership. He did, however, retain the aura of someone who carried the best traditions of the AAUP in his head, and it was as keeper of the collective memory that he was called on to perform rewriting chores. Until he turned to the extramural freedom issue, no one in the AAUP questioned his efforts, but on that issue, Maguire turned out not to be on the same wavelength as many of his colleagues.

Maguire was, to the $n$th degree, a gentleman of the old school, a person convinced that there were certain things the civilized members of society simply did not say or do, and that the university, as the epitome of civilization, had special reason to contain speech within acknowledged chalk lines. Moreover, although he quarreled as a civil libertarian with the presidents' seeming indifference to the spectre of censorship, he shared their discomfort with the inflammatory rhetoric of academics on the political left and with the militant behavior of certain adherents to the AAUP's union rival. Just before he took on his rewriting assignment, he and other AAUP leaders had been accused by a left-wing faction on the AAUP Council of dragging their heels in the investigation of a cause celébre of that period-the dismissal from Yale of an outspoken radical, Jerome Davis-and of helping to fashion a case report that whitewashed the administration of that University. ${ }^{88}$ The accusation was in fact unfounded: Maguire's influence had waned before the Davis case arose. But what Maguire thought of the likes of Davis suggests where he might have come out if he had been more involved. "While my training has been liberal," he told this author in 1961,

I must confess to fundamental conservative impulses. Were I president, with Professor Davis a member of my faculty, I am sure that his performance would arouse my resentment. To me it seems impossible that a man who talks and writes so much can be thoroughly careful, sound and wise. But, of course, one of the functions of a university is to suffer fools patiently. ${ }^{89}$

The emotions stirred up in him by the Davis affair-a genteel aversion checked only in part by a persevering tolerance-probably had not subsided when he cocked his pen at the extramural freedom text.

Maguire took as his point of departure the presumption that a faculty member in the role of citizen does not shed the obligations and responsibilities he assumes in the role of teacher or investigator. A customer in a millinery shop tries on but one hat at a time, but to Maguire, "the college or university teacher is at once a citizen, a member of a learned profession and an officer of an educational institution." This three-in-one image was a new one, though Maguire might have thought it went far back. The 1915 Declaration did assume that statements made by faculty members in all three roles could acquire material significance in hearings designed to test their

88. 1936 case folder, Yale University-Davis (AAUP files).

89. Interview with John M. Maguire (January 22, 1960) (verbatim record of five tapes in possession of the author). 
professional fitness, but there was a difference between denying that categorical immunity attached to speech on certain topics or in certain forums and asserting that no academic role ever eclipses or displaces any other. Giving evidentiary value to all academic verbal acts in an internal hearing did something to undermine the dictum that academics were entitled to "precisely" the same freedom as other citizens, but positing a multiple persona that merged all academic roles and attendant responsibilities made that dictum much harder to sustain, and, rather than cling to a foolish inconsistency, Maguire let the dictum go. This did not mean that he drew no distinctions between civic and professional expressions. He did write that, when a college or university teacher "chooses to speak or act as a citizen, he should be absolutely free from professional or institutional censorship." These words might seem to preserve half the 1915 loaf, retaining the idea of institutional neutrality but rejecting the idea of guild control. In fact, they accomplished little; no sooner was the principle stated than it crumbled under the ethical baggage carried by the two other coterminous roles.

But [the faculty member's] special position in the community imposes special obligations .... As a man of learning, he should never forget that the public may judge his whole profession by his utterances. As an educational officer, he must remember always the public inclination to identify him with his college or university and the unusual influence which his status gives him. Hence we must at all times be scrupulously accurate, must exercise appropriate restraint and good taste, and must make every effort to indicate that he is not an institutional spokesman, but expressing individual views. The price of freedom is perpetual personal responsibility for the welfare of his college or university, and of his profession. ${ }^{90}$

Having to be conscious of these obligations "at all times," the academic could not be entitled to special protections at some times; the everlasting "man of learning" and "educational officer" made hash of the idea of a special civic role.

Who was to enforce these stirring, omnipresent admonitions? Maguire did not say, in so many words. But his silence on this crucial point was eloquent. He broke with the Seligman past when he refused to hold that his admonitions were mostly to be enforced by the pressure of colleagues or a peer constabulary. He took issue with the 1925 Statement when, like the AAC presidents, he made no provision for a faculty screening mechanism. What, then, remained? He did not say "no" to the idea that the enforcement of this admonitions should be entrusted to individual consciences. But he would have had to have written a vigorous "yes" to give anyone the impression that his confidence in the faculty's inner moral light went that far. Maguire shared the founders' cold-eyed realism about the foibles of academics without sharing their romantic infatuation with guild control. Accordingly, although he would have been the last to urge lay boards and administrators to turn themselves into a thought police, he did not believe that their intervention in public speech cases would violate the natural order of things. If anything, he thought that a hard and fast statement designed to bar such interventions

90. Maguire draft, 1940 Statement folder (AAUP files). 
would be both unnatural and futile. He told his colleagues that he dropped the 1925 provision for a faculty committee in speech cases because it "could be interpreted as requiring an administration to accept the decision of the [faculty] committee. That does not seem reasonable to me." 91 If this struck him as unreasonable, so too did the idea that an administration should accept the self-serving judgments of individual faculty members. Maguire's colleagues, and then the presidents read the spaces between his lines as holding that the ultimate disposition of speech cases should rest with the academic authorities, and the reticent author would never claim that he had been misunderstood on this point.

Circulated among the AAUP leaders, Maguire's draft touched off a cannonade of criticism seldom heard in this clubby sphere. Former secretary Cook, likely to pound hard when his free speech ardors were aroused, was extremely agitated. He declared that the list of admonitions abounded in ambiguous terms ("poor taste" indeed!); that effective political action was designed to arouse strong emotions and should not be held to a standard of "scrupulous accuracy"; that the verb "must" suggested binding rules of conduct rather than words of caution, the latter being the most that the monitory language of the treaty should imply. ${ }^{92}$ Himstead, still feeling his way on these issues, was subdued, but Ralph Dewey, his assistant, described the Maguire draft as "question-begging, obscure as to meaning and . . . dangerous to the profession." Some feared that the list of admonitions would improve the weaponry of college presidents who sought to remove difficult professors and were looking for any stick, while others feared that it would arm administrators and professors specifically against the raucous radicals, and that the AAUP's enemies on the left, accusing it of collaboration, would have a field day at its expense. Maguire returned fire by arguing that "if we [are] to get anywhere in having a new statement adopted, we must thoroughly convince the presidents ... of our willingness to assume responsibilities and [should not] ignore the weight of their opinions in the interest of inconsiderate faculty members." Cook pounced on this argument: "I am not speaking of the inconsiderate faculty members, but of the good men, like Laski, Frankfurter and Green, who would suffer" from the censorship Maguire would impose. Carlson defended Maguire's draft with the argument that it sought to do for professors what doctors and lawyers had done-that is, lay down norms of professional good behavior. But Tyler, breaking with his old friend on this issue, put his finger in the weakness in that analogy-the medical and legal professions had the power to discipline their own members, while Maguire handed over that crucial power to administrators. ${ }^{93}$ Maguire got the worse of this heated argument. He would remain a member of the

91. Letter, John M. Maguire to associates (October 23, 1936) (Maguire files \#10, AAUP files).

92. Letters, Walter Wheeler Cook to Ralph E. Himstead (October 12, 1937); Ralph E. Himstead to John M. Maguire (November 16, 1937); Ralph Dewey to Ralph E. Himstead (October 28, 1937) (all in AAUP files).

93. Letters, John M. Maguire to Ralph E. Himstead (November 18, 1937); Walter Wheeler Cook to Ralph E. Himstead (December 1, 1937); Anton J. Carlson to Ralph E. Himstead (November 3, 
association for another decade, but his reputation among his colleagues would not recover from their criticisms, and he would never be called upon again to interpret basic AAUP philosophy.

It would be logical to suppose that Maguire's critics received his contribution with thanks, dropped it into the dead letter file, and promptly forgot all about it. What actually happened tells us why history is not a branch of logic. First of all, the Maguire draft, while it could be repudiated, could not be buried. It belonged to the meeting as a whole, and it was entered, as promised, on a record distributed to everyone, including the AAC presidents, who sang its praises. Second, because of the long intervals between all the meetings and the press of business at the next meeting, a year elapsed before the Maguire draft came up for consideration en banc. This delay gave the AAUP time to ask itself whether it had more to lose by renouncing the draft (with the possibility that this would lead to a split that would destroy the conference) or by doctoring it so as to retain most of its words but weaken its effect. The AAUP negotiators decided on the second course, reasoning that progress on the vital tenure front justified a prudent pullback on the academic freedom front, provided the retreat did not turn into a rout. Third, they refined the Maguire admonitions to the point where they could convince themselves they improved on any that had appeared before. Where the AAUP founders had placed themselves high above the hurly-burly of public life by expressing their dislike for "hasty" and "exaggerated" public utterances, and the AAC presidents' plea for the "serious" and the "sober" read like an ode to gloom or a temperance tract, the words Cook and Carlson chose seemed less cranky and more precise. This is the version that would wind up in the final text:

Hence [the college or university teacher] should at all times be accurate, should exercise appropriate restraint, should show respect for the opinions of others, and should make every effort to indicate that he is not an institutional spokesman.

To be sure, these adjectival changes, though more than cosmetic, did not change Maguire's basic thrust. But the editors did find a way to alter the thrust without defacing the entire text. In President Wriston's view, once it was agreed that verbal conduct was a proper target of academic legislation and that guild regulation of that conduct could not work, the only escape from undesirable institutional censorship would be unconditional selfenforcement. Consequently, he suggested that the AAUP add the following sentence to the Maguire draft: "The judgment of what constitutes fulfillment of these obligations should rest with the individual." The AAUP jumped at the suggestion, not only to take the threat out of the text with one swift move, but to cut all the Gordian knots into which the issue of extramural freedom had been for so long entangled. ${ }^{94}$

1937); H. W. Tyler to Ralph E. Himstead (November 11, 1937), all in 1940 Statement folder (AAUP files).

94. Letter, Mark Ingraham to Ralph E. Himstead (January 27, 1940), attributed the selfenforcement proposal to Wriston. See Wriston, 25 AAC Bull at 115-16 (cited in note 64). 
Put on the table at the third meeting held in October 1938, the amended AAUP draft drove a wide wedge between AAC locals and cosmopolitans. To President Dennis and his small-college allies-E. J. Jacqua, President of Scripps College and Meta Glass, President of Sweet Briar College-the idea that faculty members should be the final judges of their own indiscretions seemed dangerous and absurd. Like the AAUP professors, they too drew lessons from case experience-from tales of faculty members antagonizing potential donors with tactless comments, dispensing insider information so as to embarrass their institutions, exploiting colleague and student discontent to foment rebellion-and they very much doubted that the boors, the snitchers and the malcontents would be able to recognize, let alone reform, themselves. Dennis, the ringleader of the opposition to the AAUP on the issue of selfenforcement, fastened on the idea of setting up a nationwide external tribunal, perhaps made up of representatives of the AAC and the AAUP, to take jurisdiction over cases in which academics were accused of speech improprieties in public forums. He thought this would be a statesmanlike middie way between the folly of trusting faculty members to guide their own tongues and pens, and the danger of allowing administrators to serve as a board of censors. Wriston was withering in his opposition to this idea. He argued that most presidents, like himself, were too preoccupied with their own problems to go fishing in the troubled waters of other presidents; he pointed out that the verdict of an external tribunal would have to be carried out by local campus authorities, so that the whole scheme was really tantamount to institutional enforcement, albeit in several steps. Most of all, he took exception to the argument that faculty members were by character incapable of speaking with decorum and good sense. "It is with the individual that responsibility rests in other professions," he would write. "So let it be with us."95 Wriston and Capen, plus a solid AAUP contingent, carried the day for self-enforcement. With this controversy and the long-pending tenure issue resolved, the conferees were able to agree on the entire package, and the so-called 1938 Statement was sent to the governing boards for ratification. ${ }^{96}$

Dennis could not sway the negotiating conference, but he did prevail at the highest level of the AAC. It is unclear just why the AAC board of directors took such strong exception to the self-enforcement sentence. Dennis tried to convince them that the sentence as it stood would debar not only institutional discipline but also administrative criticism of untoward speech. It is hard to imagine that the logic of this argument-giving one group the right to judge requires another group to seal its lips-won over many board members. More likely, those who had not been privy to the conference discussions and had to deduce intents from texts found the juxtaposed ideas in this passage

95. Wriston, 25 AAC Bull at 115-16 (cited in note 64).

96. Report of Joint Conference of Representatives of Association of American Colleges and American Association of University Professors on Academic Freedom and Tenure (October 17-18, 1938). Minutes of the Meeting of October 17-18, 1938, 1940 Statement folder (AAUP files). 
troubling. Faculty members who promised to be on good behavior and who then insisted that they must decide whether they kept their promise might well have seemed to be more than a little disingenuous. Faculty members who conceded that the reputation of their college hung on their every wink and whisper but who would not let the college take actions in its own defense might well have appeared to be playing games with words. By combining Maguire's high-flown pledges with a growled "don't tread on me," the AAUP seems to have leased the worst of several worlds, seeking two desiderata in a way that appeared duplicitous, hoping to placate but sounding arrogant, and in the end seeming too clever by half. It was not easy to cut Gordian knots with a single swipe of a rusty sword.

A year after their first accord was rejected, the AAC and the AAUP met again to try to salvage a project on which they had lavished so much time and energy. Wriston and Capen did not attend the November 1940 meeting; Carl Wittke, dean of Oberlin College and a former chairman of Committee A, and W. O. Tolley, president of Allegheny College, replaced them as spokesmen for what might be called the permissive position on extramural freedom; Dennis came to hold forth as mulishly as before on his pet project. The AAUP delegation included two standbys, Carlson and Cook, who had some of the fight knocked out of them by the debacle of two years before; a number of newcomers who left no mark; and Himstead, now three years into his term of office and much more self-confident than before. Himstead had not taken a strong position on the extramural freedom issue, in part because he did not follow all its sinuosities, but mostly because he rated this issue distinctly secondary to the issue of tenure, on which he was determined to take an unyielding stand. Without clear ideas about how to break the impasse but determined to do it, he stumbled on a solution halfway into the final session:

$\begin{array}{ll}\text { DENNIS: } & \text { All I ask is that there shall be some impartial tribunal to try the case } \\ \text { of a professor who acts so foolishly that he risks his usefulness . . } \\ \text { I do not want a man to be an absolute judge in his own case. } \\ \text { HIMSTEAD: } \begin{array}{l}\text { If a professor's utterances are a reason for dismissal . . we already } \\ \text { have a provision [under the tenure rules] for an institutional hearing. }\end{array} \\ \text { DENNIS: } & \text { Isn't that reserved for a professor who kills somebody ... ? } \\ \text { HIMSTEAD: } & \text { No. If a member of your faculty would start making speeches } \\ \text { advocating free love, you have provisions for handling it right here } & \\ \text { in the [tenure and due process] section of the Statement. }\end{array}$

The two retired to put their newfound harmony into treaty language, and they returned with a set of interpretive comments that would be pinned to the 1940 Statement as a footnote to its paragraph on extramural freedom. At the core of these comments lay Himstead's breakthrough concession:

if the administration of a college or university feels that a teacher has not observed the admonitions [the reference was to the Maguire piece de resistance as amended] and believes that the extramural utterances of the teacher have been such as to raise grave

97. Minutes of the Joint Conference of Representatives of the Association of American Colleges and American Association of Professors on Academic Freedom and Tenure at 22 (November 8 , 1940), 1940 Statement folder (AAUP files). 
doubts concerning his fitness for his position, it may proceed to file charges under Paragraph (a) of the section on Academic Tenure.

To administrators who did avail themselves of the judicial machinery of the tenure system, Himstead and Dennis addressed these warnings: "[i]n pressing such charges the administration should remember that teachers are citizens and should be accorded the freedom of citizens"; "in such cases the administration must assume full responsibility" and the AAUP and AAC "are free to make an investigation." The conference unanimously endorsed this compromise, and one of the great stumbling blocks in the way of ratification by the AAC governing board was removed.98

Afterwards, many AAUP members and officials would be uncertain about just what the pact-partners had agreed to. One extramural freedom case in particular would show that what had been settled in script had not necessarily been settled in many minds. In 1960, the Board of Regents of the University of Illinois dismissed Leo F. Koch, an assistant professor of Biology, for writing a letter to a student newspaper condoning premarital sexual intercourse between consenting students (Himstead's hypothetical curiously come alive!). To convince the AAUP investigators and the academic world that Koch's academic freedom had not been violated by its action, the board came up with findings that tracked the 1940 Statement: Koch, it held, had not adhered to the standards of "accuracy," "restraint," "respect for others," and dissociation from his institution prescribed by that code for extramural utterances, and he could thus be validly discharged after a due process hearing for not living up to his academic responsibilities. The AAUP team of investigators, headed by Professor Thomas I. Emerson of the Yale Law School, plus every member of Committee A, agreed that the Illinois administration had not accorded Koch adequate due process; for this reason, the association voted for censure. But a sharp internal division arose over whether any institutional sanction-even the relatively mild one of a reprimand, which had been recommended by a faculty hearing body-could be imposed on Koch under the 1940 Statement. Professor Emerson, taking vigorous exception to the view that only "responsible" extramural utterances were protected under the insigne of academic freedom, considered the passages in the 1940 Statement so marred by backing and filling as to be almost meaningless. Several members of Committee A, calling attention to the postulate that academics should be accorded the freedom of citizens, argued that the 1940 Statement did not sanction occupational punishments for allegedly untoward public speech. But a majority of the committee, after reviewing the history of failed attempts to find alternatives, concluded that the interpretive footnote plainly did say that a failure to adhere to the verbal standards laid down for extramural utterances could be used by an administration as a ground for dismissal. ${ }^{99}$

98. Footnotes, 1940 Statement, 1984 AAUP Red Book at 4-5 (cited in note 1).

99. The University of Illinow, Report of the Ad Hoc Committee, and Academic Responsibility; Statement of the Ad Hoc Committee in the Koch Case, 49 AAUP Bull 25-43 (1963). 
From a yet more distant perspective, it seems abundantly clear today that the Committee A majority in the Koch case was correct. Thanks to Himstead's late-hour concession, the 1940 Statement did permit the regents of a university to enforce its exhortations through regular disciplinary procedures. And more than Himstead realized, his conversion had broad consequences. For one thing, by admitting that extramural utterances could be grist for the ordinary mills of academic discipline, Himstead stripped them of the unique credentials they had held in AAUP's eyes since 1915. Nor was their privileged position restored by anything agreed to in the footnote. The warning that the AAUP reserved the right to intervene in such cases was no more than a fig leaf: the AAUP was free to intervene in any kind of case and few believed that an administration would be intimidated by the AAUP's threat to loose the fateful lightning of its terrible swift sword. The other warning-that administrators pressing charges should accord faculty members the rights of citizens-was at most a plea for judicial leniency, not for prosecutorial restraint, since it was designed to accompany rather than deter a disciplinary action. For another thing, if the words uttered by professors in a civic context are punishable, a fortiori so too are words spoken in their classrooms. As clarified by Himstead, the admonitions of the 1940 Statement were thus not just right-sounding but empty; they were precepts without teeth.

To the academic freedom purist, the AAUP may seem to have suffered an ignominious defeat through this compromise. In reality, this long-time defender of academic freedom actually scored a number of victories, though these do not leap to the eye of the perfectionist. First of all, it headed off an attempt by the presidents to detach extramural freedom from its academic freedom moorings. This may look like a Pyrrhic victory to those who think that the civic utterances of academics find a safer haven in the first amendment to the Constitution than in a spongy professional norm. But even today it may be doubted that the law is the citizen-academics' shepherd who invariably sees to it that they shall not want, and it is certain that untying the triadic bundle in 1940 would have weakened the professional defenses of academics whose public words came back to haunt them in a disciplinary action on their home grounds. Secondly, the AAUP's concessionary posture may well have done more for academic freedom in the long run than would the less-yielding stance it at first preferred. In the world of the Henry Wristons, academic freedom was a cultural familiar in need of little explanation and no apology, but in the large expanse of academic America represented by E. C. Dennis, it was still a cultural stranger, tolerated for its reputation but eyed with puzzlement and mistrust. The formulations the AAUP came up with-the role analysis, the monitory language, the enforcement give-back-should be read not simply for their noetic meaning, but as placating gestures designed to acculturate academic authorities to a concept they still regarded as somewhat alien. And it seems safe to conclude that its words did have that designed effect, that academic freedom did find a 
comfortable home in all corners of the nation, precisely because it did not embolden faculty members to do their worst or utterly shackle academic administrations.

Finally, as a practical matter, Himstead's key concession-that the machinery set up to test charges of professional shortcomings and misdemeanors may be used to test a charge of irresponsible public utterance too-did not put extramural freedom at significantly greater risk than before. Indeed, Himstead was confident that invoking this procedure would lessen the frequency of such prosecutions. His deprivileging of civic utterances, like the waiving of conclusive faculty verdicts and the general decline of a guild esprit, did contribute to the slide toward ordinariness that is so prominent a part of this story. But "ordinary" in this instance did not imply "routine." Even as the two associations were locking horns over constraints on extramural freedom, they were engaged in a parallel conflict over the reform of academic tenure. The further judicialization of the dismissal process, one of the key reforms Himstead urged upon the presidents, promised to deter wrongful punishments for civic speech as well as to discourage the wrongful use of that instrument for other ends. If Himstead took concession to be the better part of valor in the freedom area, he did so largely because he assumed it would be made innocuous by a breakthrough he hoped to accomplish somewhere else.

\section{IV}

\section{REFORM}

In the mid-1930s, an AAUP survey of a representative sample of American academic institutions, 125 in all, revealed that close to half of them appointed all their faculty members on an annual basis. Mostly in the public sector and largely concentrated in the South and West, these thoroughgoing annualists were not all cut from the same cloth. Some of them clung to the Draconian practice, common in public institutions during the nineteenth and early twentieth centuries, of vacating all positions at the end of every year and reappointing only those former incumbents who could pass a de novo test. Most of the others renewed the appointments of their faculty members, especially those of high professorial rank, with little re-evaluation, and sometimes as a matter of course. But all of them, whether or not they were engaged in the vascular opening and closing of positions, did keep all of their faculty members on short-term, renewable appointments, and so could be labelled, even by the definitions of that time, as lacking a system of tenure. ${ }^{100}$ The rest of the 1930s sample-mostly Eastern and private institutions, together with the flagship public universities of the Midwest and Westgenerally offered all faculty members at the rank of full professor (and quite often the rank of associate professor too) an appointment that bore no date of expiration and was variously termed "continuous," "indefinite," or

100. Malcolm W. Willey, Depression, Recovery and Higher Education 80-81 (McGraw Hill, 1937). 
"permanent." By definition, such an appointment was continued without having to be explicitly renewed; in many places, such an appointment would not be discontinued unless a serious dereliction, rather than a somewhat reduced level of performance or an inability to meet a raised level of expectation, came to light. But seldom was it understood that such an appointment could not be terminated unless the holder of it had been formally accused of an offense, the accusation had been weighed in a campus hearing, and the accuser-invariably the administration-had carried the burden of proof. And hardly ever did it mean that charges intended to bring about the termination of such an appointment had to be heard by a committee of the affected teacher's peers, which would judge their veracity and seriousness. Did academics so appointed have tenure prior to 1940? Surely so ancient an idea as tenure did not wait until well into this century to make its first American appearance. Tenure as a well-grounded expectation-that is to say, as a deservedly confident belief that one's appointment would be allowed to continue until resignation or retirement-was real enough: it fed on a variety of authoritative signals, informal understandings, personal ties, and calming precedents. Tenure as a retrospective fact-in other words, long incumbency-was not uncommon, thanks to the salubriousness of the academic work environment as well as to the issuance of nonexpiring employment contracts. But tenure as we know it today-as a set of due process rights that go with the acquisition of a certain status, everyone being eligible for that status after serving a fixed number of years-did not exist or else existed only in seed even in the mainstream universities. There is much to be said for what may be called "premodern" tenure. A deeper sense of security may well be imparted by the trust formed in face-to-face relationships than in the distrusts embodied in formal rules. But Gemeinschaft works better than Gesellschaft only when it is not severely tested-in the interstices of human crises, so to speak. Once the members of a community have a falling out and the sentimental bond is broken, the separated parties are likely to rue the lack of clarity, rationality, predictability, and formal justice that are the gifts of modern tenure rules.

Overall, there were many more assistant professors and instructors than full and associate professors among the faculty members surveyed in the 1930 s. Where it was presumed that the dignity of a senior professorship forbade the periodic testing of its incumbent, it was also presumed that the inexperience or as yet unfulfilled promise of a junior faculty member warranted appointments of short duration-three years at the most, one year as a rule. Superficially, it would appear that a majority of the junior faculty members in institutions practicing premodern tenure were on all fours with every faculty member in institutions without tenure, in that they too could be turned out of office by inaction (when their contracted-for time ran out) and sub silentio (without a finding of cause or even a required explanation). But those who lived the low-rank life in places that gave tenure to their highranked members faced an opportunity and experienced a frustration not 
known to their undifferentiated neighbors. The presence of two classes of tenants in the house of learning, one elevated by rank above the other and therefore spared the periodic threat of eviction, had the potential of turning the lower floor into a proving ground from which qualified persons could be lifted out of insecurity on the elevator of promotion. But few institutions of higher learning set a limit on the number of times short-term leases could be renewed, or fixed a particular moment in the employment cycle when those found meritorious would rise to their just deserts. As a result, a system was created in which teachers of lesser rank, appointed time and again, could compile as many years of service as their higher-ranking colleagues without ever gaining surcease of the pain of temporariness or an end to bouts of springtime nervousness when contract renewal time came round. ${ }^{101}$

These flaws in the American tenure system were not disclosed to the AAUP for the first time in the 1930s; they had been evident to it since its founding, indeed they had done much to precipitate its founding. And the AAUP had wasted no time in advancing practical solutions. In 1915, the Seligman authors, concerned about the lack of judiciality in the dismissal process, proposed that all eligible faculty members "should be entitled, before dismissal, to have the charges against them stated in writing in specific terms" and-a major demand-that they should receive a "fair trial" on those charges before a judicial body composed of their institutional peers. "At such trial," they went on to say, "the teacher accused should have full opportunity to present evidence"; in cases where the charge was professional incompetence, they were to be able to introduce the testimony of departmental colleagues and fellow specialists from other institutions. But not everyone was eligible for such a hearing-not by a long shot. To the founders, the only faculty members entitled to peer-run hearings before dismissal were the holders of permanent appointments (the rest received refusals of reappointment, not dismissals), and the only faculty members

101. This overview of the status of academic tenure during the negotiation and the adoption of the 1940 Statement is based on a number of national surveys: an incomplete though suggestive survey conducted by $W$. W. Cook for the association in 1931, 18 AAUP Bull 255-57 (1932); stenographic minutes of Council discussion of that report, Council Minutes (AAUP files); Wildred M. Mallon, Faculty Ranks, Tenure and Academic Freedom, 39 Nat'l Catholic Educ Ass'n Bull 177 (1942); Loya Metzger, Professors in Trouble (doctoral dissertation, Columbia Univ, 1978) (study of institutions with and without written rules of tenure during the 1930s); Cecil Winfield Scott, Indefinite Teacher Tenure: A Critical Study of the Historical, Legal, Operative and Comparative Aspects (Columbia Univ Press, 1934); National Education Association, Tenure Policies and Procedures in Teacher's Colleges (NEA Press, 1943); Paul Clare Reinert, Faculty Tenure in Colleges and Universities from 1900 to 1940 (St Louis Univ Press, 1946). For a brief history of academic tenure, see Walter P. Metzger, Academic Tenure in America: A Historical Essay, in William R. Keast, ed, Faculty Tenure 93 (Jossey-Bass, 1973). For surveys that followed the framing of the 1940 Statement and that may measure changes it may well have helped to bring about, see Clark Byse, Tenure in American Higher Education: Plans, Practices and the Law (Cornell Univ Press, 1959); Martin A. Trow, The Distribution of Academic Tenure in American Higher Education (Carnegie Commission on Higher Education, 1972); W. Todd Furniss, Faculty Tenure and Contract Systems: Current Practice (ACE Special Report) (July 27, 1972); Paul Dressel, $A$ Review of the Tenure Policies of Thirly-One Major Universities, 44 Educ Rev 243-53 (July 1963); Frank Atelsak, Tenure Practices at Four Year Colleges and Universities (ACE, 1980). 
entitled to permanent employment were professors, associate professors, and "everyone above the grade of instructor . . . after ten years of service."

These proposals were in direct response to the state of affairs uncovered by the first investigations. To counter the claim of one private university that a veteran assistant professor had no more right to a formal hearing than the merest tyro in that rank, the Seligman authors argued that after a while-after a long while-the disability that ordinarily attached to a low professorship should cease to exist. Several public universities claimed that they were legally incapable of making contracts for longer than the time period covered by legislative appropriations; to this the Seligman group replied that governing boards could make long-term commitments which, if not legally enforceable, would nevertheless be morally binding. In many cases on the first year's docket, a president's word in the trustees' ears was the sum of the dismissal process. Responding to this immediate reality but drawing on very distant, even medieval, precedents, the Seligman group proposed that a faculty hearing body be interposed between administration and governing boards to break into and monitor their auricular communications. ${ }^{102}$

But this generation of AAUP leaders was too locked into the assumptions of their time to propose deeper-going reforms. For one thing, beyond insisting that specific charges be put in writing, that relevant evidence should be introduced and that the proceeding be "fair," they had nothing to say about how the faculty should conduct a dismissal hearing: without further elucidation, they left it to the judgment of scholars to set the rules for such proceedings. Their low interest in procedural instruction was a reflection of their high degree of professional self-romanticization. They simply took it for granted that faculty members were equipped by career-long training to weigh evidence with abundant care and treat their colleagues justly. Significantly, they called for "fairness," a quality hard to define but evident to gentlefolk when they saw it, and not for "academic due process," a phrase of later coinage, which mimicked the methodology of the courts.

Similarly, the 1915 criteria of eligibility for the judicial benefits of tenure, though obviously at odds with blanket denials of tenure, did very little to relieve the blocked mobility that could beset a two-tier system. The conventional wisdom of 1915 held that faculty rank, a sure testimonial of current merit, should be the key determinant of eligibility for tenure. The founders did not fundamentally disagree. They proposed that all full and associate professors should be given a permanent appointment regardless of their length of service; that it should take as many as ten years before a statute of limitations could be invoked to offset the inconsequence of an assistant professorship; and that this veterans' bonus should not be extended to instructors, who under their proposals were allowed to labor indefinitely in that lowly grade.

102. 1915 Declaration at 41-42; Appendix $A$ at 405-06 (cited in note 13). 
Even in this undeveloped state, the reforms with which the young AAUP became identified met with considerable resistance. Before World War I, administrative opposition centered on the role reversal implicit in a faculty hearing of dismissal charges. Calling on the president to be a charge-maker rather than a discharge-maker, the AAUP was asking that he place himself on a level with the professor he accused and play the part of a humble adversary before a faculty clad in judicial robes. This was asking a great deal at a time when the academic executive ego was not exactly of the shrinking kind. ${ }^{103}$ After the war, some experts in industrial work psychology held that job security hurt productivity and that everyone, even professors, performed better when pressured by market threats.

All the more, then, was the AAUP gratified by the AAC's measured acceptance of parts of its tenure program. The AAC team headed by Dean Cole had signalled that there would be no attack on the principle of tenure at the Washington conference-and there wasn't any. Both sides readily agreed that "[i]t is desirable that termination of a permanent or long-term appointment for cause should regularly require action by both a faculty committee and the governing board of the college." "Desirable" fell a good deal short of "necessary"; still, the AAUP had reason to be pleased that presidents, who might have insisted that their wishes in the matter of dismissals should be treated as foregone conclusions, consented to any faculty intermediation at all. Beyond this, the two sides took a small step toward making the dismissal process more judicial when they agreed that "in all cases where the facts are in dispute, the accused teacher should always have the opportunity to face his accusers" before "all bodies that pass judgment upon his case." In this acknowledgement of the importance of confrontation, the idea of academic due process for the first time glimmered. ${ }^{104}$

Glad that their worst fears were pleasantly disappointed, the AAUP leaders were not disposed to lament their unsuccesses. In reviewing their handiwork before the AAUP council, they passed over the fact that they had ducked the critical issue of tenure eligibility. The 1925 Statement referred to "temporary" or "short-term" appointments, which could be terminated merely by giving timely notice, and "permanent" or "long-term" appointments, which could be terminated only for cause and after a full-dress hearing. It said nothing, however, about what entitled a faculty member to pass from one state to the other. The AAC presidents had no desire to make tenure one of the privileges of rank, possibly because they feared that so many faculty members had been paid in the psychic currency of title in lieu of the coin of the realm that the linkage would result in massive and unanticipated enfranchisements. The AAUP professors made no move to link academics'

103. For examples of presidential resistance to peer review in dismissal cases, see Andrew $S$. Draper, The University President, 97 Atlantic Monthly 35 (1906); C. R. Van Hise, The Appointment and Tenure of Lniversity Professors, 12 AAU J Proc 61-62 (1910); Merle Curti, 2 The University of Wisconsin; a History, 18+8-1925 43, 55-56 (Univ of Wisconsin Press, 1949).

104. 1925 Statement at 330,331 (cited in note 45). 
status to years of service, probably because they thought it unprofessional to award a high honor to mere longevity. Thus, both sides could derive some satisfaction from a statement about "being" that ignored the question of "becoming.,"105

The Great Depression brought the AAUP to a turning point in its thinking about tenure reform. Unlike later downturns in the American academic economy, this unprecedented one did not, even in its most severe early years, cause the dismissal of many tenured faculty members. The chief economies exacted at the expense of their group came from cuts in nominal salaries (in deflationary times this did not produce a commensurate cut in purchasing power), slower rates of promotion from associate to full professor, and attrition. It was hard to tell whether the paucity of dismissals was attributable more to the protections of tenure than to the professional and social standing of the tenured. There was no doubt, however, that without the armor against adversity provided by a permanent appointment, the less well-established junior faculty could be naked before the storm. To be sure, hard times did not take their worst toll on this group by contracting their ranks. Too many institutions held on to inexpensive low-level beginners to allow their demographic profile to change dramatically. But many short-term contracts did run out and were not renewed, and these were bound to have chilling demonstration effects for all. Throughout the country, the competition for nontenure positions tended to turn new Ph.D.s into scramblers for openings that demanded heavy workloads at cut-rate pay, and turned the currently employed into supplicants for continued favor. In times of relative prosperity, external opportunity could take the edge off internal discontents. During the Depression years, this safety valve went seriously out of kilter: for some time, both the vacancy rate at lower rank levels and the rate of tenure promotion sank sharply; afterwards they rose somewhat but did not return to former levels. ${ }^{106}$

The plight of the academic underclass during the Depression gave the AAUP a strong compassionate reason for reopening negotiations with the $A A C$; that it and the AFT were vying at this time for the affections of that constituency gave it a pragmatic sanction for doing so as well. Still, when they first met with the AAC presidents after the onset of the Depression, the AAUP professors were not yet ready to recommend a radical change of course. Maguire's reworking of the 1925 agreement still treated transience and permanence as categories without connective tissue. A tentative restatement

105. The AAC presidents wanted to allow for renewable contracts of considerable duration as a third option between transience and permanence: the AAUP used a syntactic form ("or" rather than "and") that accepted long-term appointments only as a possible alternative to short-term and permanent ones but did not accept them as a standing tertium quid. The AAUP professors did not force the issue, apparently convinced that even a static statement on eligibility rebuked the idea that an entire faculty might properly consist of temporary help, and in this way did tenure a good turn. But this formulation surely did not give the untenured army in tenure-granting places a good turn: for all these pact-writers had to say, permanent temporariness could continue to be their lot.

106. Willey, Depression, Recovery and Higher Education, chaps 2-3 (cited in note 100). 
of the AAUP's position drawn up by Cook and used as a working draft for the next two meetings moved away from 1925 but could not shake the major presuppositions of 1915. It called for the tenuring of everyone in the upper professional ranks and everyone in the ranks below who had put in more than a certain number of years of service. This two-variable set was rife with complexities and complications, which the conferees puzzled and battled over for some time. ${ }^{107}$

It took the AAUP general secretary almost two years fully to convince his colleagues that tenure should be completely divorced from rank and tied exclusively to years of service. It had not been obvious to Himstead that an award given once or twice in a lifetime and almost never repossessed was a more accurate gauge of academic merit than the repeated votes of confidence implied in a string of reappointments. What did become obvious to him was that no criterion of eligibility other than a temporal one offered the junior members of the profession so many ramified and vital protections. The program of tenure reform that became his passion had a logic to it, which can be laid out in enumerated steps:

1. AAUP investigators often ran up against the administrative contention that old hands on unrenewed term appointments gained nothing from their length of employment that would entitle them to a dismissal hearing. This argument often served to frustrate an inquiry into underlying administrative motivations and sometimes helped administrations side-step censure. Himstead was quick to see that the best way to counter this argument was to uphold the principle that tenure rights accrue to faculty members after so many turns of the service clock and do not depend on the institution's contract and promotion policies. Destined to be called "de facto tenure," this way of liberating the tenure rights of veterans from the explicit say-so of the institution would become, after 1940, an indispensable tool of AAUP case analysis. ${ }^{108}$

2. A promotion in rank had the quality of an impromptu act; a completed work period had the quality of a rite of passage. Himstead was not the first to call this period a "probationary" one; that word, in limited academic use, was drafted into the formal AAUP vocabulary by Cook, who may have borrowed it from the Protestant ministry or from the federal civil service. Later, a few academic critics, half-facetiously mistaking its etymology, would complain that the term was rather too suggestive of the suspended sentences meted out to persons convicted of minor crimes or of the time spent in Coventry by students required to atone for high jinks or low grades. But Cook's associates

107. 1937 Cook Draft, 1940 Statement folder (AAUP files).

108. Nothing did more to focus AAUP attention on the importance of a time standard for tenure than the negative reception of its report on the Yale University-Davis case (see note 88). In it, the association had ruled that an associate professor with thirteen years of service was not entitled to a dismissal on hearing charges simply because the institution had not seen fit to promote him to tenure. Lovejoy, who was still watching out for his baby now grown up, thought this was a posture the organization dare not continue to hold. "We must decide upon what we regard as a justifiable period during which a teacher may be recognized $b y$ ' us as on probationary status." Record, 1937 Annual Meeting (AAUP files). 
thought "probationary" was an inspired loan word, admirably suited to describe the character, timing, and purpose of one segment of the employment stint. The word suggested that this period was a time of trial, not a time for coasting; that its aim was to give the novitiate the opportunities of an internship and the institution the benefits of a second look; that it was to start close to the individual's arrival and end after a finite amount of time; that it should be regular and calculable, not capricious or ad hoc. Himstead's contribution to the development of the probation concept was to stress its helpfulness to the probationer. For him, the chief benefit of this device was not that it gave the institution a chance to check its gate evaluation of recruits with knowledge acquired from closer observation, but that it gave flesh to the hope that the journeymen years of academics would be treated as pretenure years and not as a collection bin for cheap, submissive, and unhopeful labor. He hammered away at the Cook proposal because he feared that any opening of a second road to tenure through the discretionary award of title prizes would diminish the use and usefulness of the probationary scheme.

3. Not alone among his colleagues but with an inimitable doggedness, Himstead insisted that the number of years anyone could spend in probationary service should be fixed at a single maximum that would apply to every college and university in the country. The root of this ambition was not an abstract devotion to common standards (had he made a fetish of uniformity, he would also have insisted on a universal minimum) but a practical desire to shore up his program of reform at its potentially weakest points. An unending probationary period would not be a probationary period but a career-long purgatory; even an open-ended probationary period could threaten to devour most of a faculty member's working life. The fixed star in Himstead's constellation of beliefs was that the welfare of the academic profession as well as the peace of mind of the persons in it required vigilance against the evil of permanent transience. The obvious countermeasure was to cap the number of probationary years. When the presidents proposed that each institution set the cap as it saw fit, Himstead led the AAUP's resistance to the proposal, his principle objection being that a forest of probationary periods of different lengths, all equally valid, would make it impossible for the organized profession to criticize an overrun or even define excess. At the start, Himstead, like most of his colleagues, thought that five years on probation was just right; in the course of the negotiations, he went up to six; in the climactic last meeting, to appease the pact-partners, he accepted seven. He found no cabalistic magic in any of these numbers-five, six, or seven all had the desirable property of falling between the very few years of probationary service advocated by the teachers' union and rejected by the AAUP as amounting to instant tenure, and the founders' double-digit standard, which would have alienated from the AAUP most academics under thirty or thirty-five. ${ }^{109}$ For Himstead, the important thing was to establish a

109. Not every AAUP leader thought that any intermediate number would do. Cook believed that "every time we add a year, it puts us at a greater disadvantage with the teachers' union." 
broadly accepted, fixed, and universal limit to the number of years an academic professional could work in an academic institution without the protections of academic tenure, and for this purpose, while extreme numbers were to be avoided, a number of numbers would do.

4. It was not lost on Himstead that lasting impermanence could be the lot of academics even if every institution were to limit its probationary period to five, six, or seven years. A faculty member who undergoes a trial period runs the risk of being tried and found wanting-or at least unwanted. Under the constraints of the proposed reform, a negative judgment reached (with due notice) close to the end of the permitted time period would have the inescapable effect of compelling the individual to pack up and go. And then what? To try again somewhere else and, that failing, try again? The vision of junior faculty members wandering like so many Ishmaels from one academic institution to another, serving as probationers in one place until their allotted years were up and then being hired as beginners in another, was disturbing to the leaders of the AAUP, and to no one more than Himstead. The answer they came up with (it was necessarily a formulaic answer) was to provide that all the years a person spent in the profession were to count as probationary years of service in the current institution, although by mutual agreement no more than three years need be so credited. Included in the 1940 Statement, the carryover credit provision added another computation to the time-counts featured by a modern tenure system. The seven-year rule would become broadly accepted (except in some of the highest reaches of academe), but the. notion that probationary years spent at institution $X$ were fungible with probationary years spent at institution $Y$, when each institution is morally certain that it is superior to the other, was to live a troubled life.

5. Most of the conceptual differences between Himstead and his colleagues were worked out before the important October 1938 meeting with the presidents; one difference, however, was not. This had to do with the acceptability of the policy of "up or out," a short-hand used to describe the systematic refusal by an institution to retain and thus grant tenure to a terminal probationer it does not think highly enough of to promote. Himstead became deeply alarmed when he learned that Harvard and Yale, in a major remodeling of their tenure rules begun in 1938, welded the principle of tenure after a period of probation to the practice of automatic extrusion barring a coincident rise in rank. ${ }^{110}$ Such a policy, he lamented, would cause high turnover among the younger faculty, since their ranks were overcrowded and the finances of academic institutions did not permit much population growth at the top. He surmised that the expellees from Harvard and Yale would not find it difficult to land new positions, but he dreaded to think of

Wriston and Capen, as anti-union as any of their colleagues, agreed, and beseeched their colleagues not to press for the highest possible number lest a battle be won but a war be lost. Minutes of the Joint Conference, October 1938 (AAUP files).

110. Academic Tenure and Promotion in a Siluation of Increasing Equilibrium, papers presented by Dean George H. Chase of Harvard University and Dean Edgar S. Furniss of Yale University, in Association of American Universities, +2nd Annual Conference, 98-106 (Univ of Chicago, 1940). 
what would happen to the refugees from such a policy if it were generally adopted by colleges and universities and they could not count on being resettled by trading on the reputations of their past employers. For him, the proper policy was "in or out": at the end of the probationary period, faculty members may stay with tenure or else leave, but if they stay they may do so at as low a rank as instructor and with no advance in pay. He tried to get colleagues to agree and he wanted the negotiated draft to show that "up or out" was "not in harmony with our principles." 11 A number of his confreres begged to disagree. "What difference does it make to our Association," asked Mark Ingraham, if Harvard's authorities "don't want anybody they cannot promote?" "We are interested in the probationary period," not in the grounds for judging tenure-worthiness after that course is run. Laprade noted that, under their new rules, Harvard's authorities were "forcing themselves to make up their minds in a much shorter time [eight years] than they ever did before" and were thus meeting a critical AAUP objective. Arthur N. Holcombe, Professor of Government at Harvard and a council member, tried unsuccessfully to budge the general secretary by dilating on the AAUP-ishness of the new rules and by emphasizing that the President of Harvard, James B. Conant, had just been appointed to the AAC commission where the AAUP could depend on his being a force for good. ${ }^{12}$

The text of the 1940 Statement shows that this disagreement ended in a stand-off. "After the expiration of a probationary period, teachers or investigators should have permanent or continuous tenure .... Notice shall be given at least one year prior to the expiration of the probationary period if the teacher is not to be continued in service after the expiration of that period." These words do not prohibit "up or out": if the institution wishes to clothe tenure with the trappings of title (or a jump in monetary compensation or a more ample fringe), it is entirely at liberty to do so. But neither do these words prohibit or even discourage "in or out"-Himstead's concession to frugality in the interest of security. Institutions that would justify tenure quotas on the ground that they could not afford to pay for more tenured professors would have themselves, not the 1940 Statement, to blame.

Amid these efforts to reform the rules of tenure, where did the AAUP's pact-partners stand? No one should be astonished to learn that the AAC presidents were taken aback by the unfolding of a blueprint for tenure reform that went far beyond the 1925 Statement and the limited amendments to it that had been broached in the early sessions, or that they raised objections to it, one serious enough to threaten the negotiations. But to anyone acquainted with the contemporary discourse on this subject, it is striking that at no time did the AAC presidents, whether of the McConaughy or the Wriston wing, call the concept of tenure itself into question. One would hunt in vain

111. Ralph E. Himstead at the AAUP Council meetings of December 1939 and April 1940 , Council Stenographic Records and Council Letters (1940) (AAUP files).

112. Letter, Mark Ingraham to Ralph E. Himstead (February 4, 1939), Ingraham folder; Council Stenographic Records, April 1940 (AAUP files). 
through the transcripts of these meetings for a reference to tenured professors as "deadwood" or to the equation between aging and decaying that reflects the cultural gerontophobia latent in that warehouse metaphor. One would conduct a futile search for a presidential comment to the effect that universal short-term contracts, permitting periodic review and easy discharge, were needed to weed out the indolent or incompetent and prevent the hangers-on from going slack. One would occasionally find a worried estimate of the institutional cost of this or that tenure feature, but one would not find a single attempt to lay the distortions of the academic labor market or the low rate of academic productivity at the door of tenure. This was not the silence of persons too filled with loathing to enter into argument or too resigned to an evil to try to fight it; by every indication the presidents regarded tenure as beneficial and the arguments in favor of it as beyond debate. Their unanimity on this fundamental point suggests that they reflected no eccentric predilection; the executive folk wisdom of that day taught them many times over that in the faculty's easy removability lay the intrusive governing board's opportunity, and that being able to cite the obstacle of tenure enabled a president more safely to refuse to carry out its meddlesome command. The importance of this concurrence with the AAUP over fundamentals cannot be overestimated. It is safe to say that tenure would never have taken root in this country if the presidents had not been able to see the good of it, and that it would be moribund today, despite subsequent constitutional and legal developments in its favor, if they did not have strong self-interested and disinterested reasons for keeping it alive.

The AAC criticized the AAUP's new tenure plan not for its faulty philosophy but for its lack of flexibility. Maintaining flexibility in tenure matters had always been one of the AAC's primary objects in these negotiations. In the early discussions, before the AAUP's initiative completely parted company with the past, the presidents again attempted to counter the stark alternative of transient or permanent, nontenured or tenured, by introducing an intermediate category. ${ }^{113}$ During the next phase, as the AAUP plan gathered Himstead touches, the presidents looked for ways by which the tenure timetable could be bent by administrative discretion to meet individual contingencies and varying institutional needs. By October 1938, however, Wriston and his coterie of major university presidents had been persuaded that the AAUP plan should be supported and that the goal of greater flexibility, except on small numerical details, should be renounced. This defection had two effects: it cast the small college presidents, Dennis as usual in the lead, in the role of intransigents and spoilers with regard to tenure as well as extramural freedom, and it created a coalition of inflexibilists capable

113. Interestingly, in the early rounds of negotiations, Wriston joined McConaughy in proposing three statuses: permanent or continuous; temporary and probationary; and more than temporary but not permanent (which would entitle the recipient to a very long period of notice). Minutes of the Joint Conference, January 1938; letter, Mark Ingraham to Ralph E. Himstead (April 1, 1938) (Ingraham folder, AAUP files). Wriston had a change of heart which he explains in Academic Freedom and Tenure, 25 AAC Bull 110 (cited in note 64). 
of winning on a hands-up vote. The tenure section of the 1938 agreement, while not as hard-set as Himstead would have wished (it advertised itself as no more than "accepted practice"), rejected all softening amendments: in a succinct paragraph, it called for a maximum period of probation of six years, universal adherence to that maximum, credit of up to three years for probationary service rendered elsewhere, and two clear-cut statuses-that of probation and that of tenure-within the ranks of every regular full-time faculty. ${ }^{114}$

This stiff-backed version of tenure reform, like the self-enforcement clause in the academic freedom section, did not survive the hostile review of the AAC Board of Directors. The board read the paragraph as proposing to confine academic administrations to a straitjacket and acted to delete it. In its place it submitted a demand for flexibility as bold as any that had been heard before: "Each institution should define with great care the probationary period and notify every appointee of its precise length and terms." Although these words implied no forsaking of either the principle of tenure or the idea of probationary periods, they caused deep consternation among AAUP leaders. Ingraham thought that they foreshadowed a return to the dependency of tenure on rank, since they treated the probationary service requirement so open-endedly; Carlson felt that if the fitness or unfitness of a person who had withstood the rigors of the Ph.D. could not be demonstrated after six years of scrutiny, "our junior faculty, and the principle of academic freedom, to the extent that it derives from tenure" will be "sacrificed to administrative sloth. . .." Himstead was beside himself. He believed that the presidents had sounded a bugle call of retreat that would take the profession back to "the anarchy prevailing before 1925." He accused Wriston of not holding up his side of the bargain-w"we accept a limit of propriety in free speech; why don't you recognize tenure?" 115 The alarmists turned out to be mistaken: the desire for flexibility, absent any deeper animus, had the power to delay, but not to kill, reform. At the November 1940 meeting, the AAUP got all the presidents to agree to the reinstatement of the 1938 language in return for tacking on an extra year to the probationary period and a written promise that the 1940 Statement would not be applied retroactively. And this time, the board of directors did not object.

Inflexible tenure reform ultimately won out in these negotiations for the same reason that it prevailed quite independently at Harvard and Yale and made a convert of the president of Brown-it offered vital benefits to the institution that flexible tenure reform would have scotched. One of these benefits was quality control. By requiring the institution to come to a definitive tenure decision at a time certain, an inflexible policy gave fewer hiding places to the academic bent for equivocation and procrastination

114. 1938 Statement in 1940 Statement folder (AAUP files)

115. Letters, Anton J. Carlson to Ralph E. Himstead (November 2, 1940); Mark Ingraham to Ralph E. Himstead (January 27, 1940); Ralph E. Himstead to Council (April 12-13, 1940); Ralph E. Himstead to Henry M. Wriston (February 2, 1940) (all in 1940 Statement folder, AAUP files). 
always likely to be exhibited when hard personal decisions were called for. By replacing the old two-track system with a single track leading to an inescapable fork, an inflexible policy reduced the likelihood that anyone, after appointment, would go long unnoticed or become a fixture of an institution without having first been judged. Judged in comparison with whom? The 1940 Statement did not say. The report of the Harvard arts and sciences faculty that helped set up its stringent tenure rules praised the opportunity they afforded to judge probationers not only in the light of their own performance or that of other Harvard probationers, but in comparison with everyone at a similar stage to whom Harvard might offer an appointment. Not every academic institution would suppose that every tenure match was Wimbledon, that every player was seeded, or that every competitor was world class. But the idea did filter down to more average institutions that control of faculty quality could be enhanced by unflinching tenure reform, and this realization was reflected in the eventual dying down of AAC small-college resistance. Inflexibility held out another benefit: it promised to cut the high cost of institutional compassion. Rather than throw their unpromotable instructors and assistant professors into the cold Depression market, Harvard had let them stay on, year after year, acquiring the sort of de facto tenure Himstead did not contemplate-that born of institutional tender feelings. But the financial cost of sheltering large numbers with dismal prospects was high, and the qualitative cost of tying up funds for quasi-charitable purposes was incalculable. On the other hand, unpostponable stay-or-go decisions, coming up like clockwork, could be just what the doctor ordered-a purgative solution to a problem of overcrowding that could be administered without remorse. Ironically, Himstead's rigidity, conceived as the salvation of the junior faculty, could in the same scheme of things serve to cast off the junior faculty, and the AAUP, for all its efforts on behalf of the academic underprivileged, would later be hard pressed to convince them that it deserved their love.

The last part of the tenure reform program inscribed in the 1940 Statement concerned procedures for dismissing tenured faculty. Still wedded to the principle of faculty hearings, the AAUP persuaded the AAC to reaffirm it (here the presidents did insist on one gesture to flexibility-faculty hearings only "if possible"). This time, no longer persuaded that justice would be done if only faculty members were asked to do the judging, the AAUP also sought and received the assent of the AAC to a number of procedural guidelines. The 1940 Statement repeated the demand for written charges, which the teacher should have an opportunity to rebut, and added the right of the accused both to the presence of an adviser who might act as counsel and to a stenographic record of the proceedings that would be complete and accessible to all parties. These were not only the first steps toward judicialization that would ever be taken by these bodies: in 1958, the AAUP and AAC would agree to preliminary hearings, limited cross-examination, explicit findings on every charge, and a formal way of articulating the medial 
judgment of the faculty with the trustees' final review. Still, the 1940 Statement's steps may be said to mark the true birth of academic due process in this country.

\section{$\mathrm{V}$}

\section{Conclusion}

Is the future of the 1940 Statement bright? One can find a multiplicity of reasons for supposing that its days are numbered. It has stepped on the toes of so many potential academic supporters-the libertarians who deplore its stand on freedom, the unionists who believe arbitration should be substituted for peer review, the many who expect more of it than it delivers and would wish it had said less on many counts-that one may wonder whether it will hereafter find anyone to befriend it. It is so out of touch with critical developments in the academic profession, such as the immense increase in the number of part-timers drawn from the casual labor market, and it is so out of sympathy with some of the current devices of academic management, such as nontenure tracks and rolling short-term contracts, that one may wonder whether the combination of a postmodern academic work force and a premodern administrative mentality will not finally do it in. But then one may also wonder how it was that these antagonistic forces, some of which are not of recent vintage, did not kill it off long ago. The possibility should not be dismissed that the 1940 Statement will endure because it serves the enduring interests of the academic profession and the academic enterprise, not to perfection, but better than anything else in existence or readily imaginable. 
